June 2001 • NREL/TP-540-30715

\title{
Vehicle Transient Air Conditioning Analysis: Model Development \& System Optimization Investigations
}

\author{
Terry J. Hendricks
}

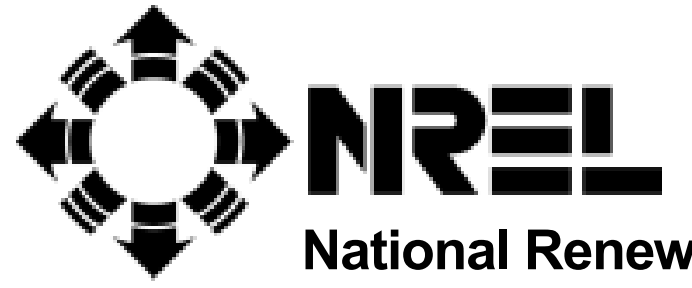

1617 Cole Boulevard

Golden, Colorado 80401-3393

NREL is a U.S. Department of Energy Laboratory

Operated by Midwest Research Institute • Battelle • Bechtel

Contract No. DE-AC36-99-G010337 


\section{Vehicle Transient Air Conditioning Analysis: Model Development \& System Optimization Investigations}

\section{Terry J. Hendricks}

Prepared under Task No. HV11.7010

.

1617 Cole Boulevard
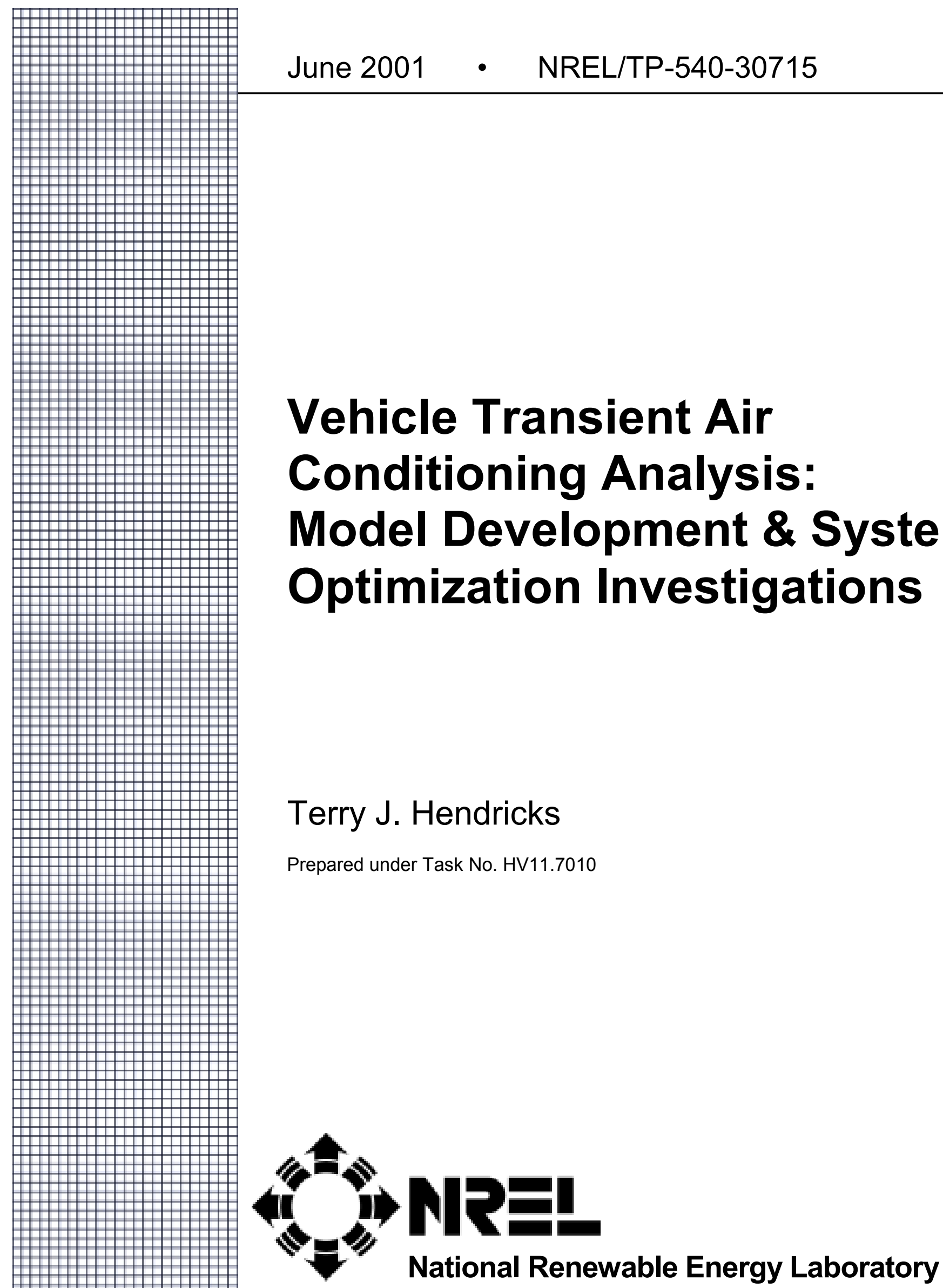

Golden, Colorado 80401-3393

NREL is a U.S. Department of Energy Laboratory

Operated by Midwest Research Institute $\bullet$ Battelle $\bullet$ Bechtel

Contract No. DE-AC36-99-G010337 


\section{NOTICE}

This report was prepared as an account of work sponsored by an agency of the United States government. Neither the United States government nor any agency thereof, nor any of their employees, makes any warranty, express or implied, or assumes any legal liability or responsibility for the accuracy, completeness, or usefulness of any information, apparatus, product, or process disclosed, or represents that its use would not infringe privately owned rights. Reference herein to any specific commercial product, process, or service by trade name, trademark, manufacturer, or otherwise does not necessarily constitute or imply its endorsement, recommendation, or favoring by the United States government or any agency thereof. The views and opinions of authors expressed herein do not necessarily state or reflect those of the United States government or any agency thereof.

Available electronically at http://www.osti.gov/bridge

Available for a processing fee to U.S. Department of Energy

and its contractors, in paper, from:

U.S. Department of Energy

Office of Scientific and Technical Information

P.O. Box 62

Oak Ridge, TN 37831-0062

phone: 865.576.8401

fax: 865.576.5728

email: reports@adonis.osti.gov

Available for sale to the public, in paper, from:

U.S. Department of Commerce

National Technical Information Service

5285 Port Royal Road

Springfield, VA 22161

phone: 800.553.6847

fax: 703.605.6900

email: orders@ntis.fedworld.gov

online ordering: http://www.ntis.gov/ordering.htm 


\section{EXECUTIVE SUMMARY}

The National Renewable Energy Laboratory (NREL) has developed a fully transient, onedimensional, thermal/hydraulic model of vehicle air conditioning systems, demonstrated that model to identify system-level design interdependencies among components, and performed multi-parameter, system-level optimization of vehicle air conditioning systems to improve vehicle fuel economy and reduce emissions. The model was developed within SINDA/FLUINT analysis software and has been integrated with NREL's ADVISOR vehicle simulation code and NREL's vehicle solar thermal load estimator code to perform co-simulations of vehicle systems, air-conditioning (A/C) systems, and cabin thermal/fluid performance for user-specified environmental and vehicle driving conditions. The transient thermal/hydraulic model takes a fundamental-principle approach to capture all the relevant physics of transient $\mathrm{A} / \mathrm{C}$ system performance, including two-phase flow effects in the evaporator and condenser, refrigerant and component inertia effects, compressor speed effects, air side heat transfer on the condenser/evaporator, vehicle speed effects, time- and position-varying heat transfer conditions, vehicle speed effects, temperature-dependent properties, environmental loading and ambient temperature conditions on the vehicle, and integration with a simplified cabin thermal model. The fundamental-principles approach of the integrated system is the only way to truly optimize the A/C system to maximize performance (i.e., minimize power consumption). This work focuses on R-134a $\mathrm{A} / \mathrm{C}$ systems, but future efforts could modify the model to investigate the transient performance of alternative refrigerant systems such as carbon dioxide systems.

The model predicts transient flow conditions, pressure and temperatures throughout the A/C system flow loop, compressor power, evaporator and condenser two-phase flow quality and heat transfer conditions, and cabin temperatures during various vehicle drive cycles and conditions. Temperatures, pressures, flow qualities, and heat transfer coefficients can be investigated as functions of time and position in the A/C system flow loop.

Various robust and powerful $\mathrm{A} / \mathrm{C}$ system optimization capabilities and studies are demonstrated and reported. System optimization studies have shown significant improvement in A/C system performance is possible through integrated system design and optimization. Recent system analyses indicate 1.8-3.5 mpg improvement is possible through integrated $\mathrm{A} / \mathrm{C}$ system optimization of interrelated component effects. Optimum, drive-cycle-dependent pressure profiles, flow quality profiles, and heat transfer conditions do exist that maximize $\mathrm{A} / \mathrm{C}$ system performance. This analysis tool is able to identify and quantify such optimum conditions. This has shown that dynamic intelligently controlled $\mathrm{A} / \mathrm{C}$ systems, based on continuous feedback of environmental and vehicle driving conditions (i.e., vehicle speed, compressor speed, ambient temperatures, humidity, and solar load conditions) and the ability to quantify system-level impacts, offer tremendous opportunities to operate vehicle A/C systems at optimum maximum performance under a variety of drive cycle conditions. This will allow NREL, The Department of Energy (DOE), and the automotive industry to increase vehicle fuel economy and reduce emissions across a wide range of light-duty vehicles, sport-utility vehicles, and heavy-duty vehicles.

Future work in FY 2001 and possibly FY 2002 will involve additional investigations in transient A/C system performance to (1) better understand optimum design conditions as a function of operating pressure and temperature; (2) better understand optimum two-phase heat transfer conditions and their relation to optimum flow quality profiles within the condenser; and (3) simultaneously optimize more system variables with more sophisticated objective functions, involving system weight, cost, cabin cooldown time, and others, in identifying optimum vehicle $\mathrm{A} / \mathrm{C}$ system designs. Future work will also focus on investigating the effects of variable displacement compressors, variable orifice valves (VOVs) and electrical-driven compressors in optimizing transient $A / C$ system performance to increase vehicle fuel economy and reduce vehicle emissions. NREL's desire also is to begin looking at specific A/C system designs of importance on specific vehicle platform projects at DaimlerChrysler, General Motors, Ford Motor Company, Visteon Corporation, and Delphi Automotive Systems and other key automotive suppliers. NREL has requested specific A/C system design data to develop project-specific A/C system models and perform A/C system optimizations relevant to industry-specific vehicle projects. 


\section{Table of Contents}

Page

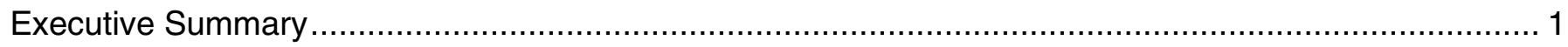

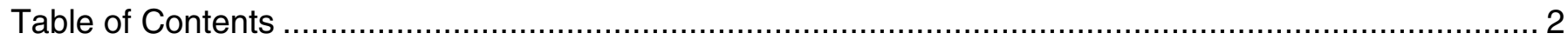

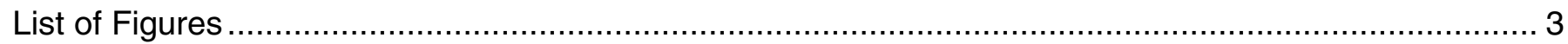

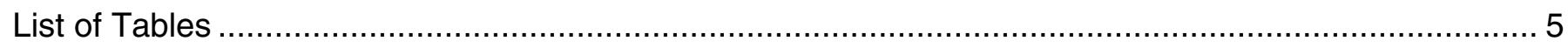

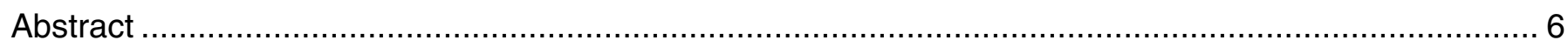

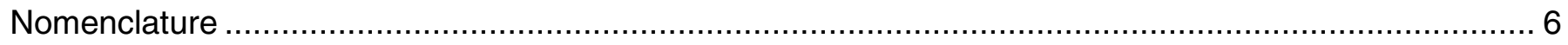

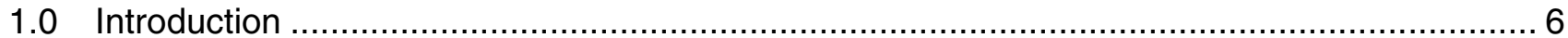

2.0 Transient Air-Conditioning Systems Model ................................................................

3.0 Component Effects ........................................................................................... 13

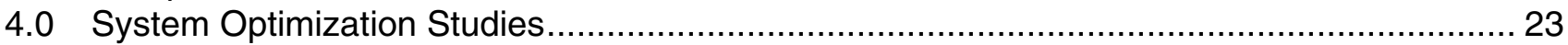

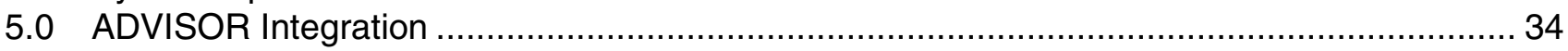

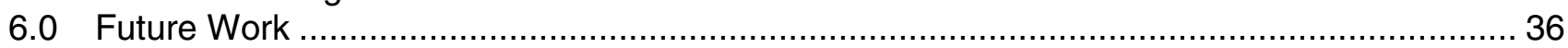

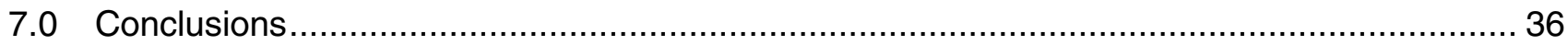

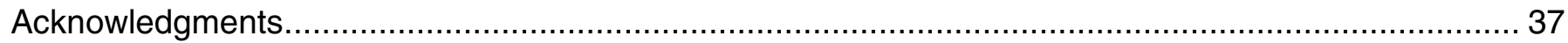

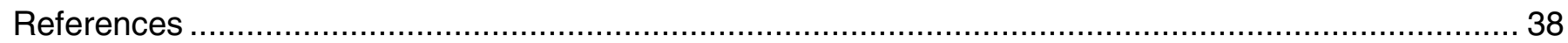

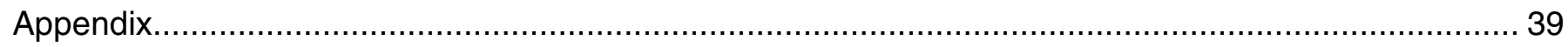




\section{List of Figures}

Page

Figure 1 Schematic Diagram of a Typical Vehicle Air Conditioning System 8

Figure 2 Schematic Diagram of SINDA/FLUINT Transient Air Conditioning System Model........ 9

Figure 3 Typical Compressor Isentropic Efficiency As a Function of Compressor Speed (Rpm) and Pressure Ratio (Pr) 9

Figure 4 Typical Compressor Volumetric Efficiency As a Function of Compressor Speed (Rpm) and Pressure Ratio (Pr)

Figure 5 Condensing Heat Exchanger Sub-Model within the Transient Air-Conditioning Model ...... 11

Figure 6 Evaporator Heat Exchanger Sub-Model within the Transient Air-Conditioning Model 12

Figure 7 Cabin Thermal/Fluid Sub-Model Coupled with the Transient Air-Conditioning Model

Figure 8 Typical Compressor Power Prediction for an SC03 Drive Cycle after Hot Soak Conditions to $75^{\circ} \mathrm{C}\left(167^{\circ} \mathrm{F}\right)$ 14

Figure 9 Typical System Pressure Profiles During the SC03 Drive Cycle after Hot Soak Conditions to $75^{\circ} \mathrm{C}\left(167^{\circ} \mathrm{F}\right)$....... 14

Figure 10 Typical Cabin Temperature Cool-Down Prediction for an SC03 Drive Cycle After Hot Soak Conditions to $75^{\circ} \mathrm{C}\left(167^{\circ} \mathrm{F}\right)$ 15

Figure 11 Compressor Power versus Time Profile for Second Industry-Standard Compressor Characteristics. 15

Figure 12 System Pressure versus Time Profile for Second Industry-Standard Compressor Characteristics.

Figure 13 Transient Flow Quality Profiles in Condenser for an SC03 Drive Cycle 17

Figure 14 Transient Flow Quality Profiles in Evaporator for an SC03 Drive Cycle. 18

Figure 15 Transient Flow Quality Profiles in Condenser for Second Industry-Standard Compressor During SC03 Drive Cycle (Current Time in Hours)

Figure 16 Transient Flow Quality Profiles in Evaporator for Second Industry-Standard Compressor During SC03 Drive Cycle.

Figure 17 Vapor/Two Phase Heat Transfer Coefficient Behavior versus Time/Position in Condenser During SC03 Drive Cycle.

Figure 18 Liquid Section Heat Transfer Coefficient Behavior versus Time/Position in Condenser During SC03 Drive Cycle. 
Figure 19 Two-Phase Flow Heat Transfer Coefficients versus Time/Position in Evaporator During SC03 Drive Cycle

Figure 20 Two-Phase/Vapor Heat Transfer Coefficients versus Time/Position in Evaporator During SC03 Drive Cycle....

Figure 21 Vapor Flow Heat Transfer Coefficients versus Time/Position in Evaporator During SC03 Drive Cycle

Figure 22 Optimum Dual Variable Solution to Maximize System COP - Optimum Transport Line Diameter and Condenser Tube Diameter 25

Figure 23 Optimum Transfer Line Diameter and Condenser Tube Diameter to Maximize System COP (Constant Initial System Pressure) 26

Figure 24 Optimum Pressure Profile Maximizing COP during SC03 Drive Cycle ..............................30

Figure 25 Optimum Flow Quality Profiles Maximizing COP during SC03 Drive Cycle …..................30

Figure 26 Optimum Pressure Profile Maximizing COP during US06 Drive Cycle.............................34

Figure 27 Optimum Flow Quality Profiles Maximizing COP during US06 Drive Cycle .....................34

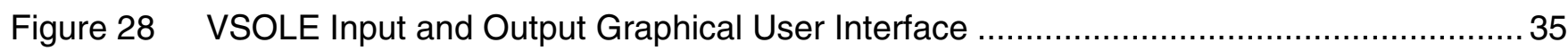




\section{List of Tables}

Table 1 Optimum Expansion Device Diameter, Transfer Line Diameter, and Condenser

Line Diameter Maximizing COP during the SC03 Drive Cycle.

Table 2 Quadruple-Variable Optimization Results for SC03 Drive Cycle Conditions (Simultaneous Optimization of Compressor Displacement, Expansion Device Diameter, Transfer Line Diameter, Condenser Tube Diameter)

Table 3 Optimum Expansion Device Diameter, Transfer Line Diameter, and Condenser Line Diameter Maximizing COP during the US06 Drive Cycle.

Table 4 Quadruple-Variable Optimization Results for US06 Drive Cycle Conditions (Simultaneous Optimization of Compressor Displacement, Expansion Device Diameter, Transfer Line Diameter, Condenser Tube Diameter) .33 


\section{ABSTRACT}

The National Renewable Energy Laboratory (NREL) has developed a transient air-conditioning (A/C) system model using SINDA/FLUINT analysis software. It captures all the relevant physics of transient $A / C$ system performance, including two-phase flow effects in the evaporator and condenser, system mass effects, air side heat transfer on the condenser/evaporator, vehicle speed effects, temperature-dependent properties, and integration with a simplified cabin thermal model. It has demonstrated robust and powerful system design optimization capabilities. Single-variable and multiple variable design optimizations have been performed and are presented. Various system performance parameters can be optimized, including system COP, cabin cool-down time, and system heat load capacity. This work presents this new transient $\mathrm{A} / \mathrm{C}$ system analysis and optimization tool and shows some high-level system design conclusions reached to date. The work focuses on R-134a A/C systems, but future efforts will modify the model to investigate the transient performance of alternative refrigerant systems such as carbon dioxide systems. NREL is integrating its transient A/C model into NREL's ADVISOR vehicle system analysis software, with the objective of simultaneously optimizing $A / C$ system designs within the overall vehicle design optimization.

\section{NOMENCLATURE}

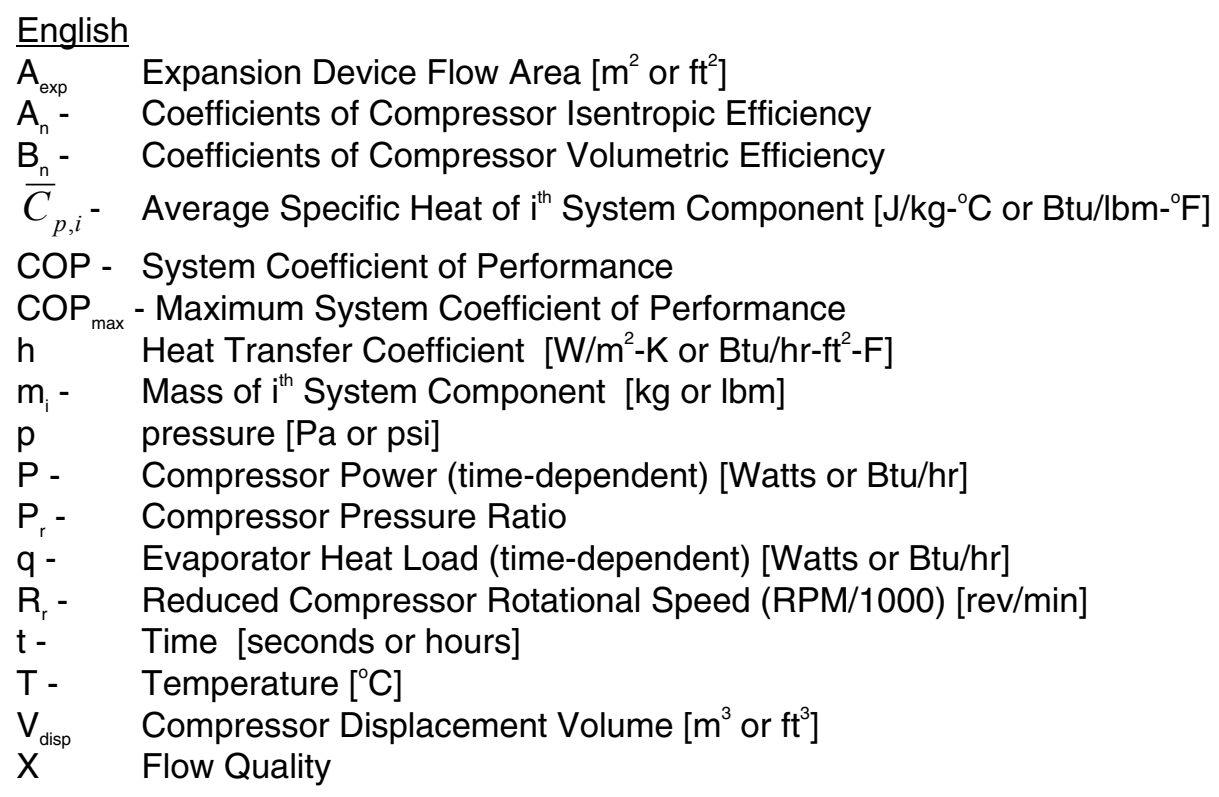

\section{$\underline{\text { Greek }}$}

$\beta_{\mathrm{i}}-\quad$ Compressor Isentropic Efficiency

$\beta_{v}$ - $\quad$ Compressor Volumetric Efficiency

$\eta$ - $\quad$ System Coefficient of Performance

\begin{tabular}{ll}
\multicolumn{2}{l}{ Subscripts } \\
\hline C & Condenser \\
e & Evaporator \\
H & High-Side Pressure \\
L & Low-Side Pressure \\
opt & At Optimum Conditions
\end{tabular}

Supercripts

$\wedge$ - $\quad$ Time-averaged quantity

\subsection{INTRODUCTION}

Major U.S. Department of Energy (DOE) objectives include developing innovative transportation technologies and systems that decrease vehicle fuel consumption and emissions across the nation, thereby reducing the nation's reliance on foreign oil consumption. Vehicle A/C systems represent the major auxiliary load on the engine 
of light-duty passenger vehicles, sport-utility vehicles (SUVs), and mini-vans. It can also be a significant auxiliary load on heavy-duty vehicles. The A/C system performance has a dramatic effect on fuel consumption and exhaust emissions. Recent studies [1] have shown that, during the SCO3 drive cycle, the average impact of the A/C system on seven light-duty vehicles was to increase (1) fuel consumption by $28 \%$, (2) carbon monoxide emissions by $71 \%$, (3) nitrogen oxide emissions by $81 \%$, and (4) non-methane hydrocarbons by $30 \%$. The A/C system experiences transient conditions throughout standard drive cycles and during typical city/highway driving patterns around the country. In particular, the evaporator load, compressor speed, refrigerant flow rate, and heat exchanger airflow rates can be variable. Knowledge of the transient $A / C$ system behavior is critical to understanding $A / C$ performance requirements, optimizing the $A / C$ system design, and minimizing its effects on vehicle fuel consumption and emissions throughout a drive cycle. Consequently, the National Renewable Energy Laboratory (NREL) and other researchers [2-6] are giving increased attention to analyzing and modeling steadystate and transient $\mathrm{A} / \mathrm{C}$ system performance.

\subsection{TRANSIENT AIR-CONDITIONING SYSTEM MODEL}

In order to more completely understand and quantify transient $\mathrm{A} / \mathrm{C}$ system performance and its impact on vehicle fuel consumption and emissions, NREL has developed a transient A/C model using SINDA/FLUNT analysis software [7] and is integrating it with the ADVISOR vehicle systems analysis software [8]. The transient, one-dimensional, thermal-hydraulic model was developed using a nominal representative $A / C$ system that was identified in discussions with NREL's automotive industry partners. This transient model captures all the relevant physics of transient $\mathrm{A} / \mathrm{C}$ system performance, including two-phase flow effects in the evaporator and condenser, system mass effects, air side heat transfer on the condenser/evaporator, vehicle speed effects, temperaturedependent properties, and integration with a simplified cabin thermal model. This model can predict typical transient $A / C$ compressor power requirements, system pressures and temperatures, system mass flow rates, and two-phase/single-phase flow conditions throughout the $\mathrm{A} / \mathrm{C}$ system flow circuit. The model currently does not calculate any fan power required to operate condenser or cabin evaporator fans.

SINDA/FLUINT analysis software is capable of rigorously analyzing the various two-phase flow regimes, such as bubbly flow, slug flow, annular flow, and the heat transfer and pressure drop conditions in both the evaporator and condenser. It contains several built-in heat transfer coefficient and friction factor correlations that are used to automatically evaluate heat transfer, pressure drop, and flow quality conditions within the $\mathrm{A} / \mathrm{C}$ system components during its system computations. SINDA/FLUINT also has built-in correlations for determining transitions between different two-phase flow regimes in the condenser and evaporator, and can easily analyze slip flow conditions that often occur during two-phase flow in these components. Accounting for slip flow conditions during two-phase flow produces an additional level of modeling sophistication and often has helped in matching "real-world" A/C system experimental data. The Component Effects section presents flow quality and flow regime results, and discusses the influence of system components on compressor power, system pressure profiles, flow quality, flow regimes, and heat transfer behavior in the condenser and evaporator.

The simplified cabin thermal model predicts cabin and panel outlet temperatures during transient cool-down periods and during steady state operational periods. The combined model predicts $\mathrm{A} / \mathrm{C}$ system and cabin thermal conditions during various drive cycles, including vehicle idle, SC03, US06 or other typical federal test and passenger-induced drive cycles. The SC03 and US06 federal drive cycles, shown in the APPENDIX, are currently incorporated within the transient $\mathrm{A} / \mathrm{C}$ model so that transient performance and optimization results can be tailored to each unique set of driving conditions. With its current integration to a simplified cabin model, the transient $A / C$ system model thereby provides the system link connecting cabin thermal comfort requirements back to vehicle fuel consumption and emissions. Future work will continue to integrate the transient $A / C$ model to higher fidelity, threedimensional cabin thermal/fluid models based on finite element computational fluid dynamics formulations.

Figure 1 shows schematic diagrams of typical vehicle vapor-compression air-conditioning systems. The type of system being modeled in this work is actually a capillary tube system that behaves similarly to the orifice tube system (Figure 1a). Figure 2 shows a schematic diagram of the transient SINDA/FLUINT model of a nominal representative $\mathrm{A} / \mathrm{C}$ system represented in Figure 1. The model consists of a nominal compressor, condenser design (heat exchanger HX3000), expansion device, and evaporator design (heat exchanger HX 6000). The model includes thermal regeneration between the expansion device and the suction line. 
The nominal compressor is characterized by a compressor displacement of $0.0002 \mathrm{~m}^{3}\left(12.2 \mathrm{in}^{3}\right)$ and representative isentropic and volumetric efficiencies. The compressor isentropic efficiency and volumetric efficiency are characterized by the following relationships respectively:

$\beta_{i}=1 .-\left[\frac{A_{o}}{P_{r} R_{r}}+\frac{A_{1}}{P_{r}}+\frac{A_{2}}{R_{r}}+\frac{A_{3}}{P_{r}} \cdot R_{r}+A_{4}+\frac{A_{5}}{R_{r}} \cdot P_{r}\right]$

$\beta_{v}=1 .-\left[\frac{B_{o}}{R_{r}}+B_{1}+\frac{B_{2}}{R_{r}} \cdot P_{r}+B_{3} \cdot R_{r}+B_{4} \cdot P_{r}\right]$

(a) Orifice Tube System

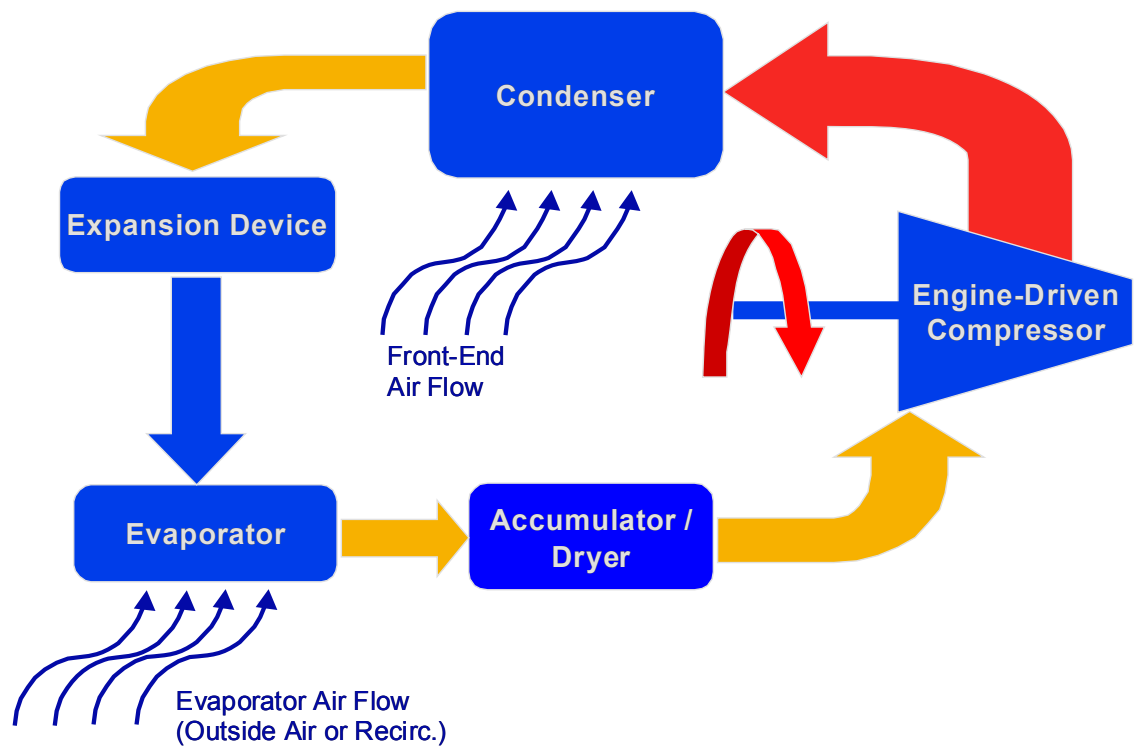

(b) Thermo-Expansion Valve (TXV) System

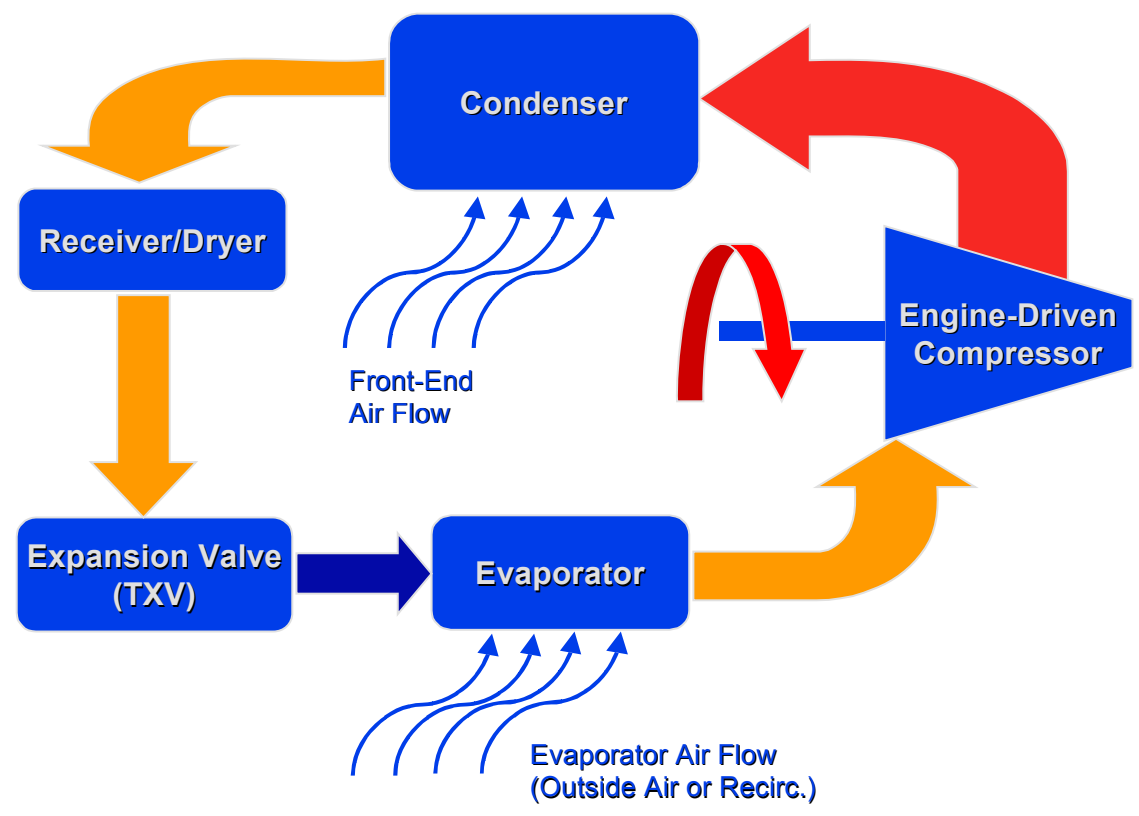

Figure 1 - Schematic Diagram of a Typical Vehicle Air-Conditioning System 


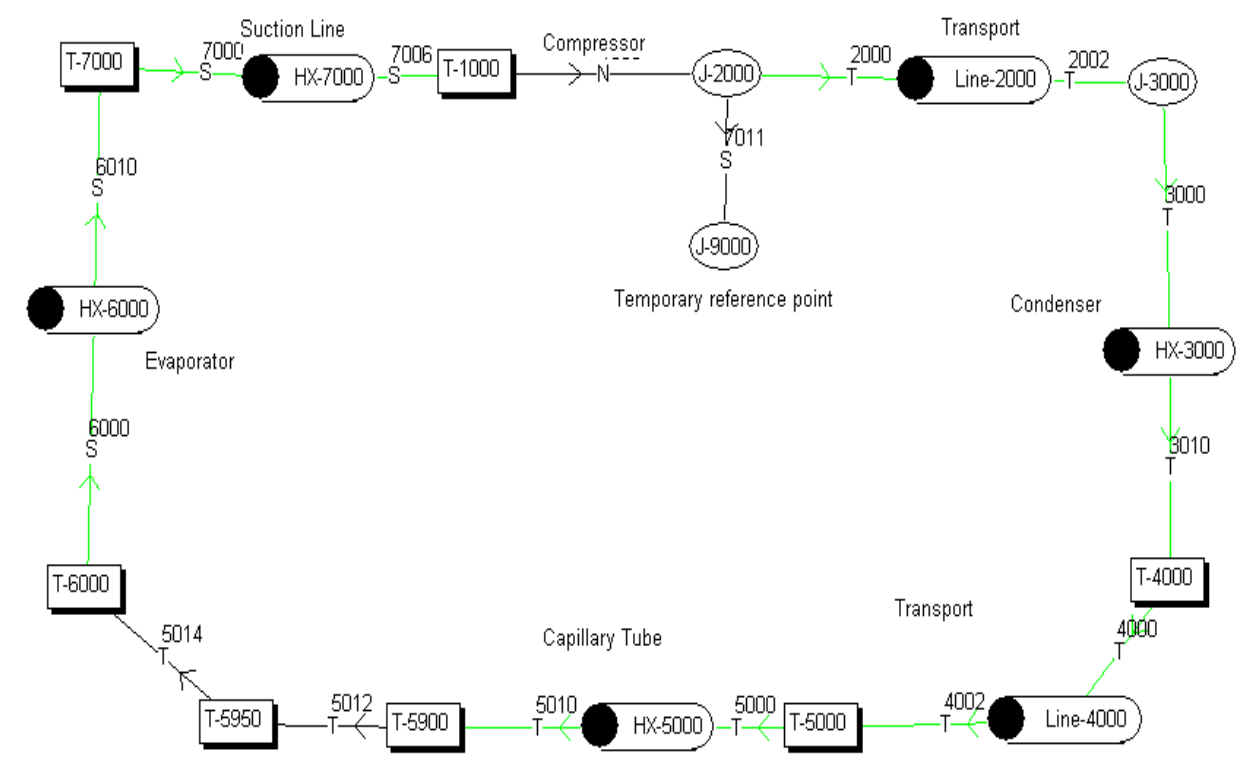

Figure 2 - Schematic Diagram of SINDA/FLUINT Transient Air-Conditioning System Model

Compressor Isentropic Efficiency vs Compressor Rotational Speed

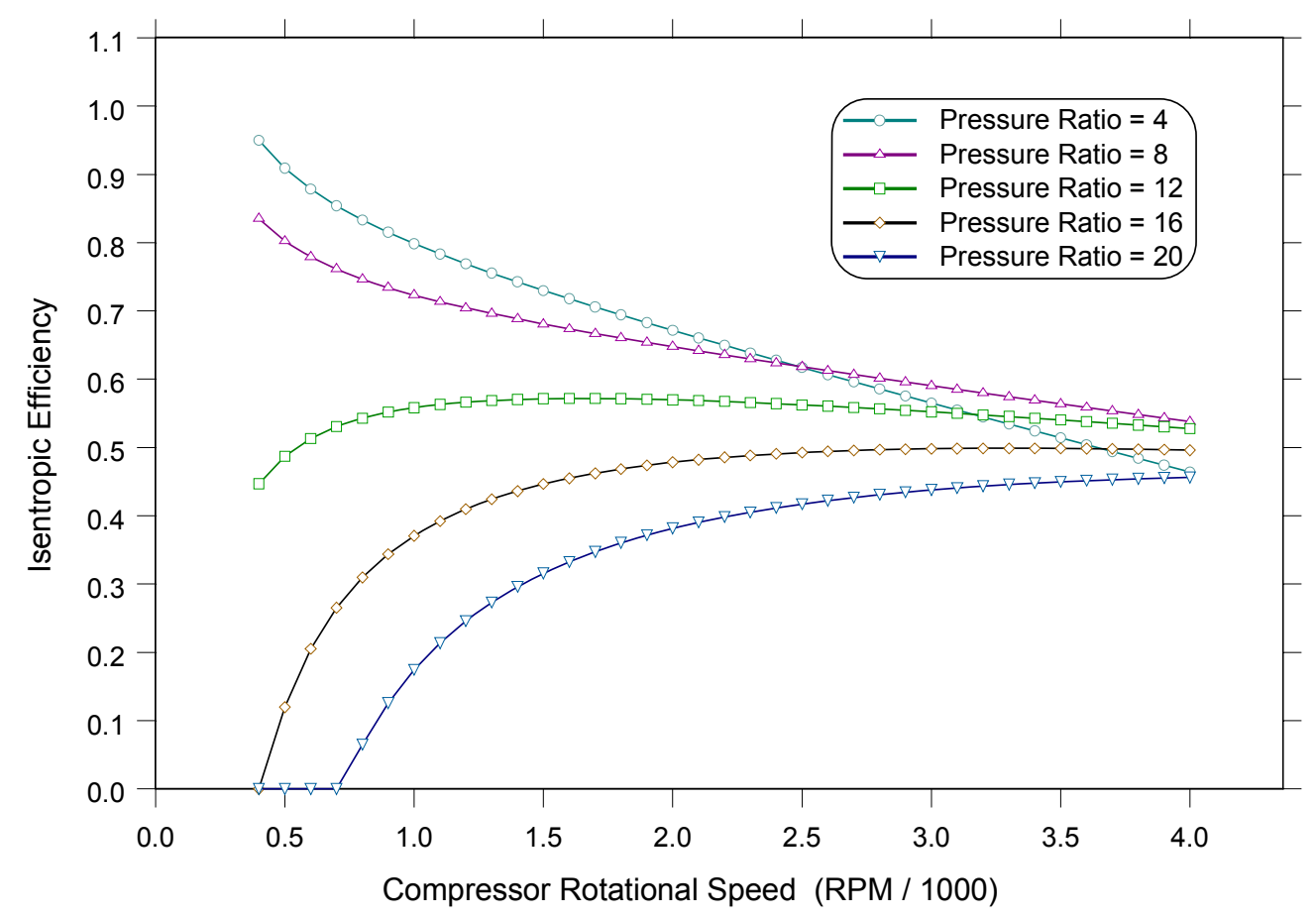

Figure 3 - Typical Compressor Isentropic Efficiency As a Function of Compressor Speed (RPM) and Pressure Ratio (Pr) 
Compressor Volumetric Efficiency vs. Compressor Rotational Speed

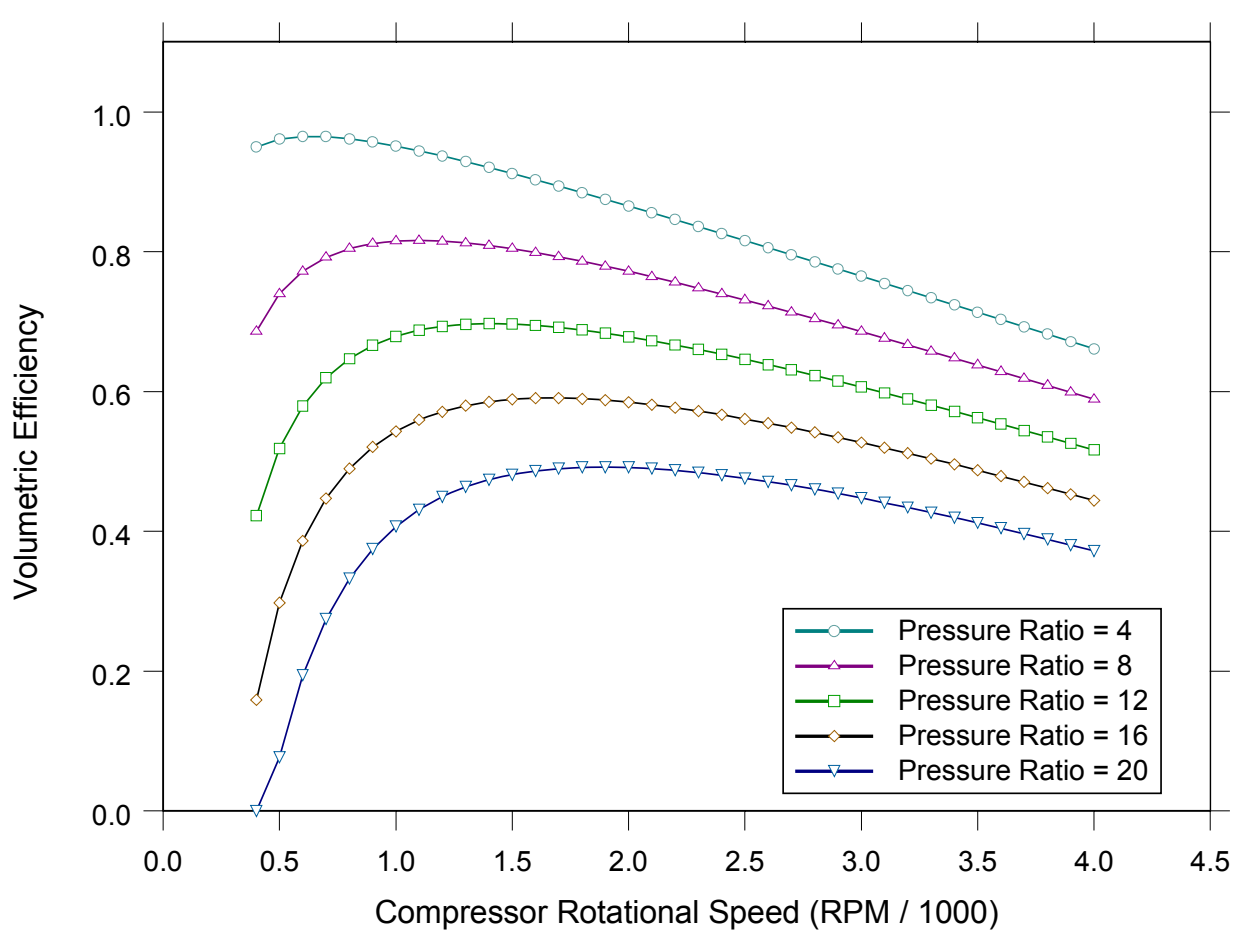

Figure 4 - Typical Compressor Volumetric Efficiency As a Function of Compressor Speed (Rpm) and Pressure Ratio $(\mathrm{Pr})$

Figures 3 and 4 are graphical representations of the predictions from equations [1] and [2]. In Figure 3 the isentropic efficiency for a typical $\mathrm{A} / \mathrm{C}$ compressor has maximum values dependent on different pressure ratios. At low pressure ratios near 4, a maximum isentropic efficiency of approximately 0.95 occurs at low compressor speeds near $400 \mathrm{rpm}$, degrading to less than 0.45 at compressor speeds near $4000 \mathrm{rpm}$. At pressure ratios of 12, the maximum isentropic efficiency of approximately 0.55 occurs at compressor speeds of near $1400 \mathrm{rpm}$, holding relatively constant at about 0.5 out to $4000 \mathrm{rpm}$. Lower isentropic efficiency simply means the compressor is operating less efficiently and therefore using more energy to accomplish the same system flow pressurization. Figure 4 shows that the compressor volumetric efficiency also has maximum values dependent on different pressure ratios. Volumetric efficiency is a measure of how efficiently the compressor supplies the mass flow through the $A / C$ system. It is very important from an $A / C$ system design perspective to understand this relationship and where optimum compressor performance regions exist. The compressor impeller inertia is currently not modeled because (1) the impeller inertia is small and responds quickly to speed changes, and (2) the transient flow conditions are more highly influenced and controlled by the compressor's inlet and outlet pressures.

The condenser heat exchanger is modeled as a serpentine-type design with 6 serpentine passes, 10 parallel channels, and a weight of $4.99 \mathrm{~kg}(11 \mathrm{lbms})$. The tube diameter was an optimization variable and determined as discussed in the following section on system optimization. The evaporator heat exchanger is also a serpentinetype design with 12 serpentine passes, a tube diameter of $0.159 \mathrm{~cm}(0.0625 \mathrm{inch})$, and a weight of $2.99 \mathrm{~kg}(6.6$ lbms). The heat exchangers were typical of designs shown in Kargilis [9]. Figure 5 shows the SINDA/FLUINT model of the condenser, with its numbering scheme for fluid lumps (i.e., volumes) and fluid paths (i.e., connectors). Figure 6 shows the SINDA/FLUINT model of the evaporator with its fluid lump and path numbering scheme. 


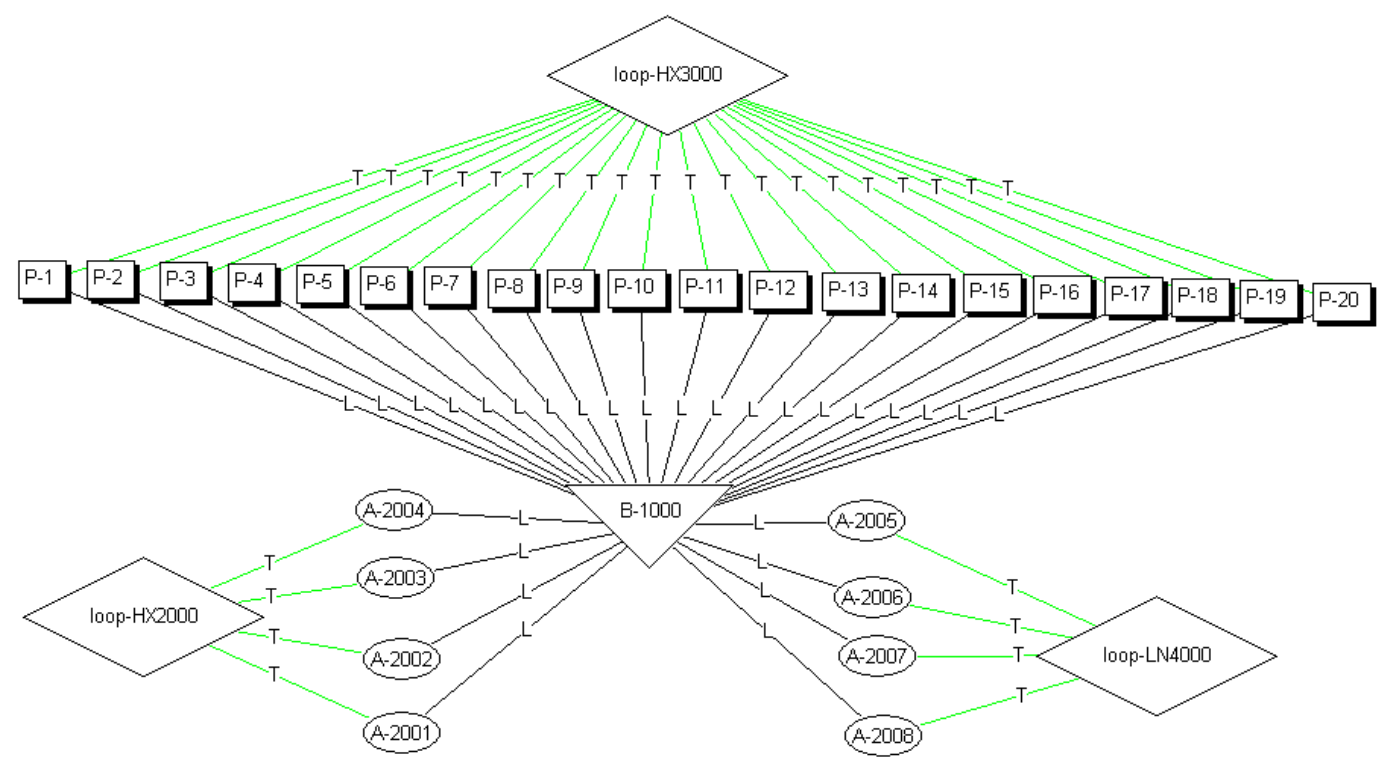

Desuperheat exchange with ambient

(a)

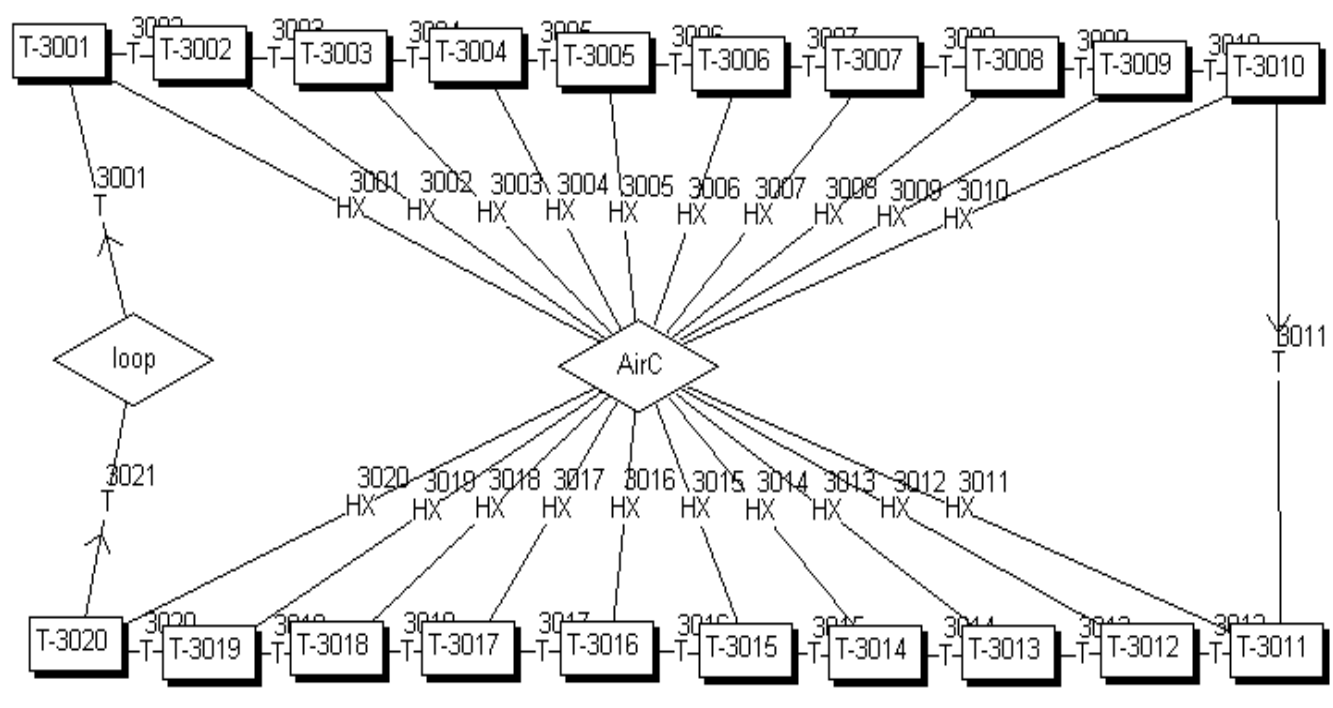

(b)

Figure 5 - Condensing Heat Exchanger Sub-Model within the Transient Air-Conditioning Model 


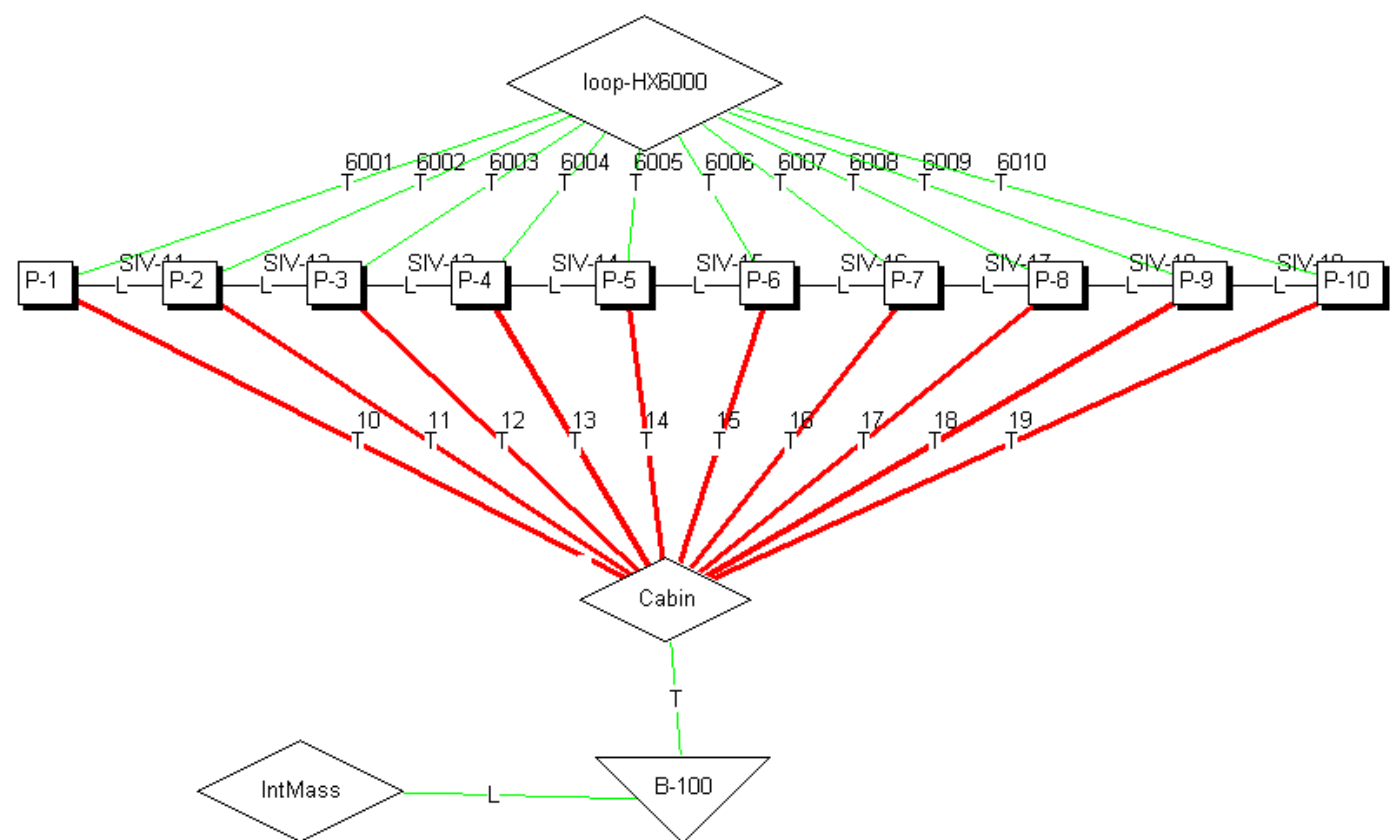

(a)

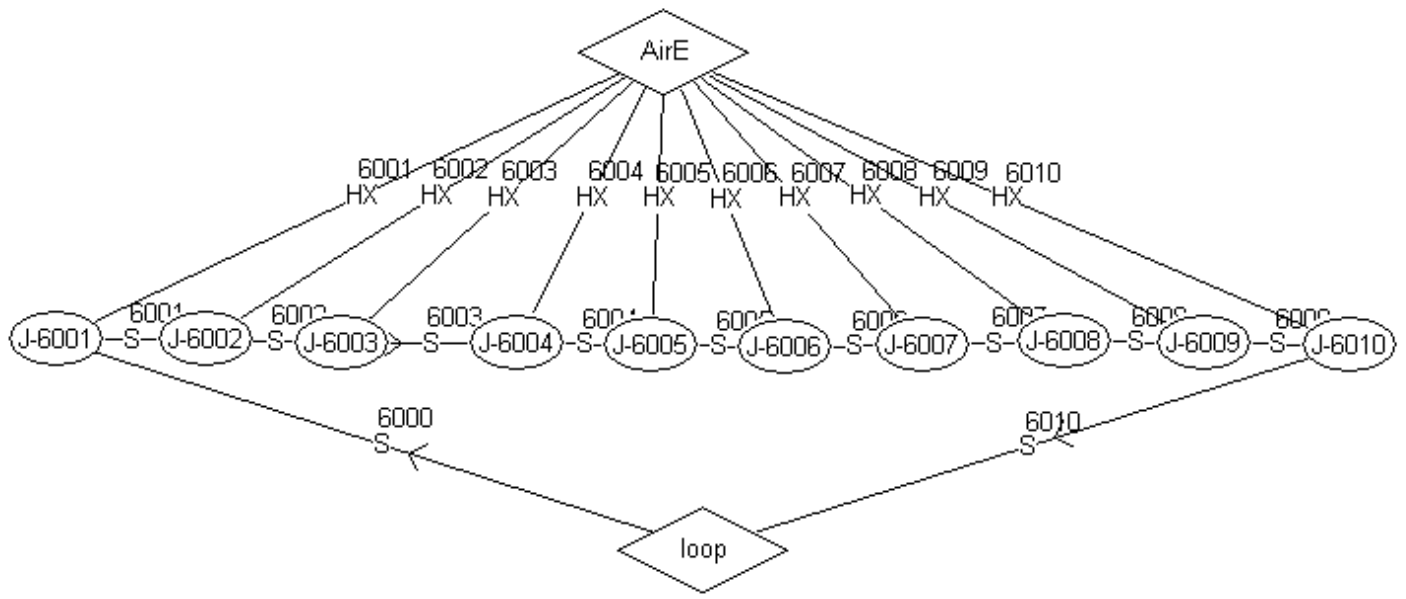

(b)

Figure 6 - Evaporator Heat Exchanger Sub-Model within the Transient Air-Conditioning Model

The transport lines shown in Figure 2 between the compressor and the condenser and between the condenser and the expansion device are critical components in the A/C system design. Their diameter and length impact system performance. Compressor characteristics and expansion device diameter are other key system parameters that impact transient system performance. The System Optimization Studies section will demonstrate how optimizing system performance (i.e., COP) is dependent not only on the component designs, but their interdependency on each other, particularly interrelationships between the compressor, condenser, and expansion device.

The transient $\mathrm{A} / \mathrm{C}$ model also contains a simplified cabin thermal model that is a two-node model consisting of the cabin air thermal mass and interior cabin hardware mass representing seats, instrument panel, consoles, and various other cabin components. The typical cabin air volume is $2.88 \mathrm{~m}^{3}\left(102 \mathrm{ft}^{3}\right)$ and the typical interior cabin hardware mass is $453.5 \mathrm{~kg}(1000 \mathrm{lbms})$ in this model. The cabin is modeled to absorb passenger thermal energy dissipation and wavelength-integrated solar thermal energy passing through the vehicle windows. The cabin model also incorporates conductive thermal energy exchange between the cabin internal air and the external ambient environment and convective thermal energy exchange between the cabin internal air and the internal cabin mass. Humidity effects, and corresponding latent thermal energy in the cabin air, also are accounted for 
during cabin cool-down periods. Figure 7 shows the schematic of the cabin thermal/fluid sub-model coupled with the transient $\mathrm{A} / \mathrm{C}$ system model.

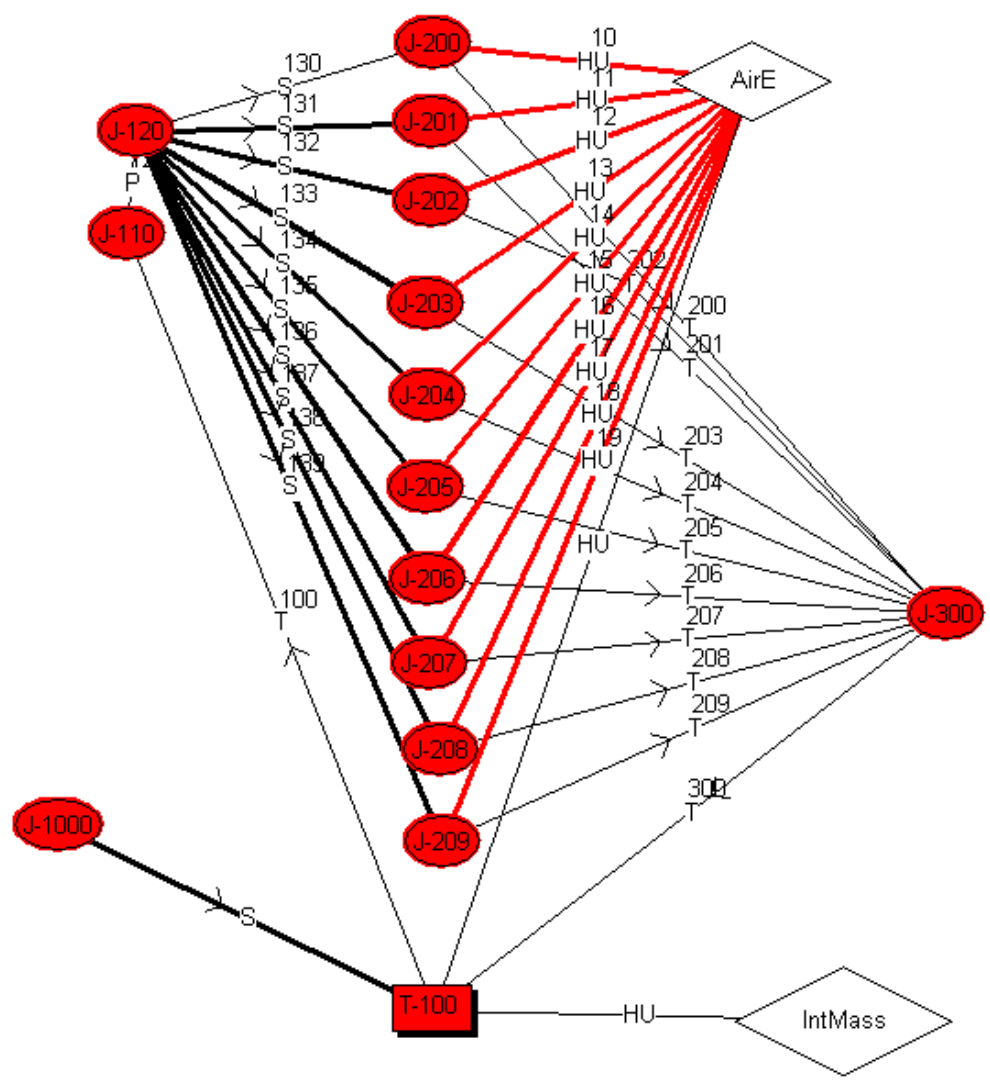

Figure 7 - Cabin Thermal/Fluid Sub-Model Coupled with the Transient Air-Conditioning Model

Figure 8 shows a typical transient compressor power prediction from the transient A/C-cabin thermal model during the 10-minute SC03 drive cycle after extreme hot soak conditions to $75^{\circ} \mathrm{C}\left(167^{\circ} \mathrm{F}\right)$. The compressor power was normalized by the average compressor power over the SC03 drive cycle, but the variation in compressor power is quite substantial. A pressure spike in the compressor outlet and condenser inlet pressures (shown in Figure 9) occurs with each compressor power spike in Figure 8. These pressure spikes are associated with vehicle accelerations in the SC03 drive cycle and are similar to those discussed by Wang et al. [3]. Figure 10 displays the corresponding typical cabin temperature cool-down prediction from the transient $\mathrm{A} / \mathrm{C}$-cabin thermal model during the same 10-minute SC03 drive cycle after the same extreme hot soak conditions to $75^{\circ} \mathrm{C}\left(167^{\circ} \mathrm{F}\right)$. The cabin cool-down is characterized by two distinct thermal time constants in Figure 10; one is a very rapid temperature decay initially that is then followed by a slower temperature decay as heat exchange between the hotter cabin hardware (i.e., seats, consoles, etc.) and the air dominates the cabin air cool-down. In the Figure 10 data, a rather high convection coefficient between the interior cabin hardware and cabin air is used, so the cabin cool-down is rather slow in this case, only reaching about $52^{\circ} \mathrm{C}\left(126^{\circ} \mathrm{F}\right)$ after 10 minutes. No system performance optimization has been done, so cool-down is not optimal in these cabin cool-down results.

The A/C model flexibility allows us to modify easily any model parameters to simulate any particular vehicle $\mathrm{A} / \mathrm{C}$ system of interest to DOE or our industry partners. These features have allowed us to investigate a wide range of vehicle transient $\mathrm{A} / \mathrm{C}$ behavior, including that in Ford Explorers and systems using electrically driven compressors.

\subsection{COMPONENT EFFECTS}

Figure 11 show the compressor power versus time profile for a second compressor design typical of a well known industry standard compressor. Comparing Figures 8 and 11 shows the compressor power profile can change dramatically, with much smaller magnitude variations, during the SC03 drive cycle simply by using a 
compressor more tailored for the specific system design of interest. Figure 12 shows the pressure profile versus time during the $\mathrm{SCO} 3$ drive cycle for the second compressor design. The pressure profile for this second compressor also shows smaller magnitude variations relative to those shown in Figure 9, reflecting the difference in compressor power behavior between Figures 8 and 11.

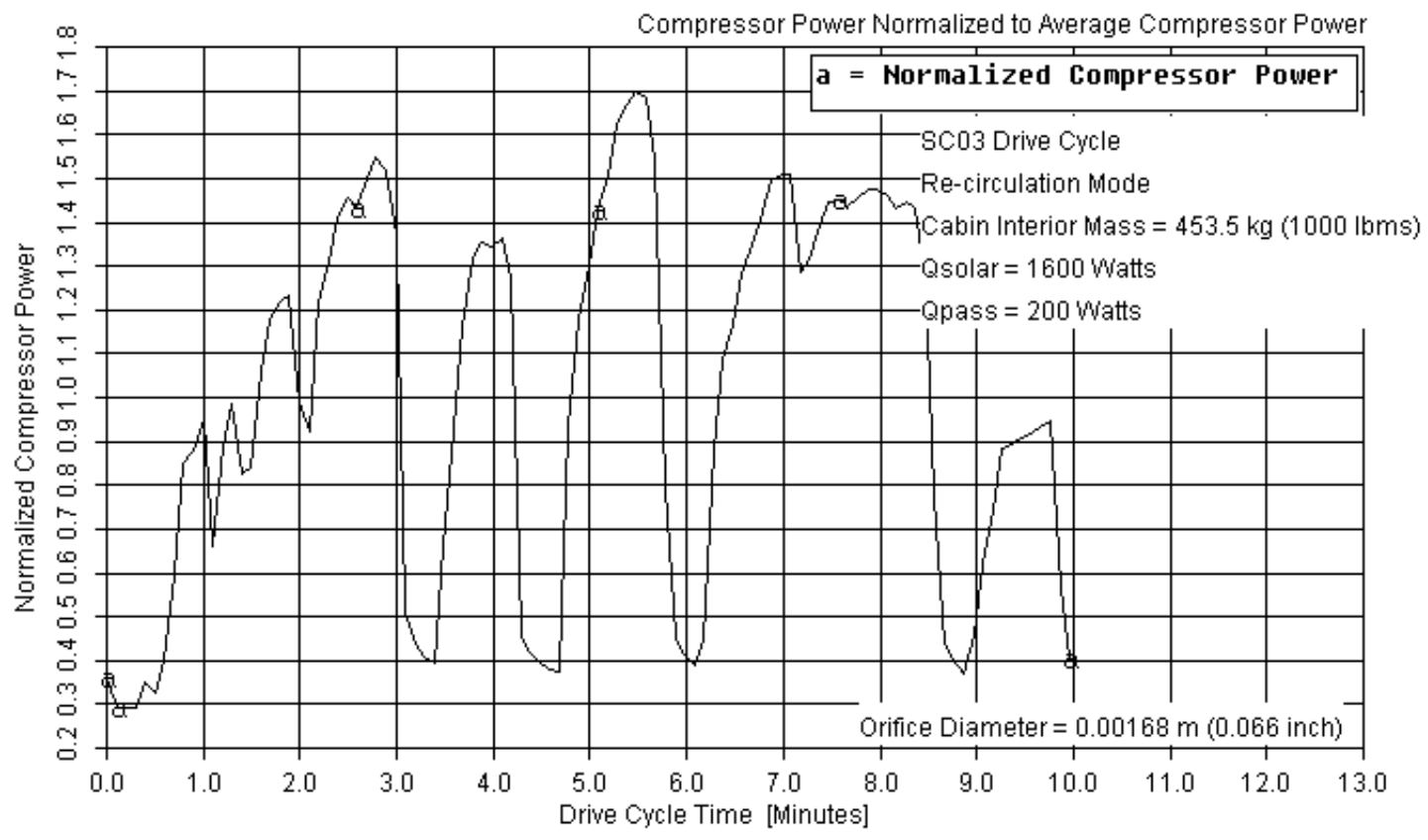

Figure 8 - Typical Compressor Power Prediction for an SC03 Drive Cycle after Hot Soak Conditions to $75^{\circ} \mathrm{C}\left(167^{\circ} \mathrm{F}\right)$.

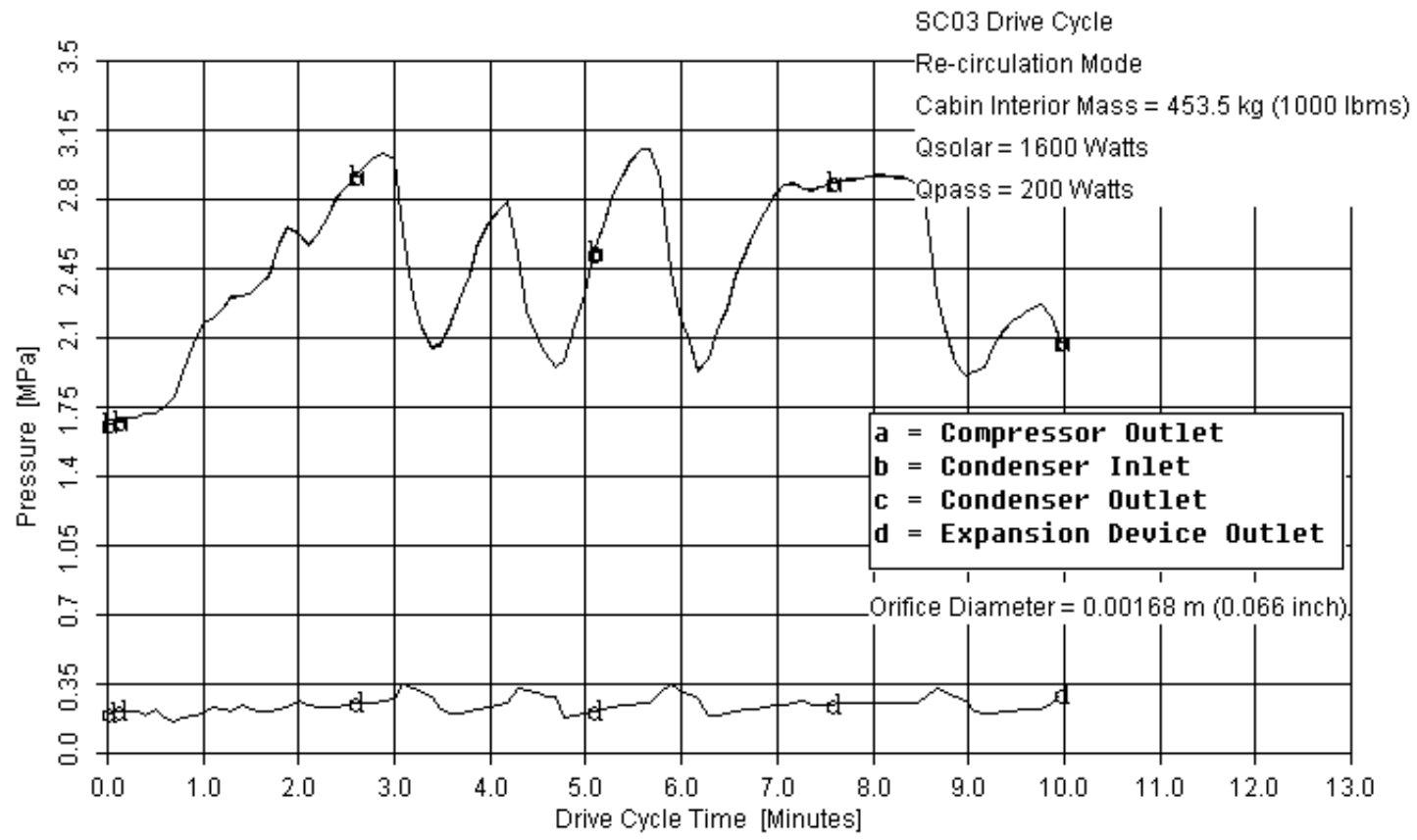

Figure 9 - Typical System Pressure Profiles during the SC03 Drive Cycle after Hot Soak Conditions to $75^{\circ} \mathrm{C}\left(167^{\circ} \mathrm{F}\right)$. 


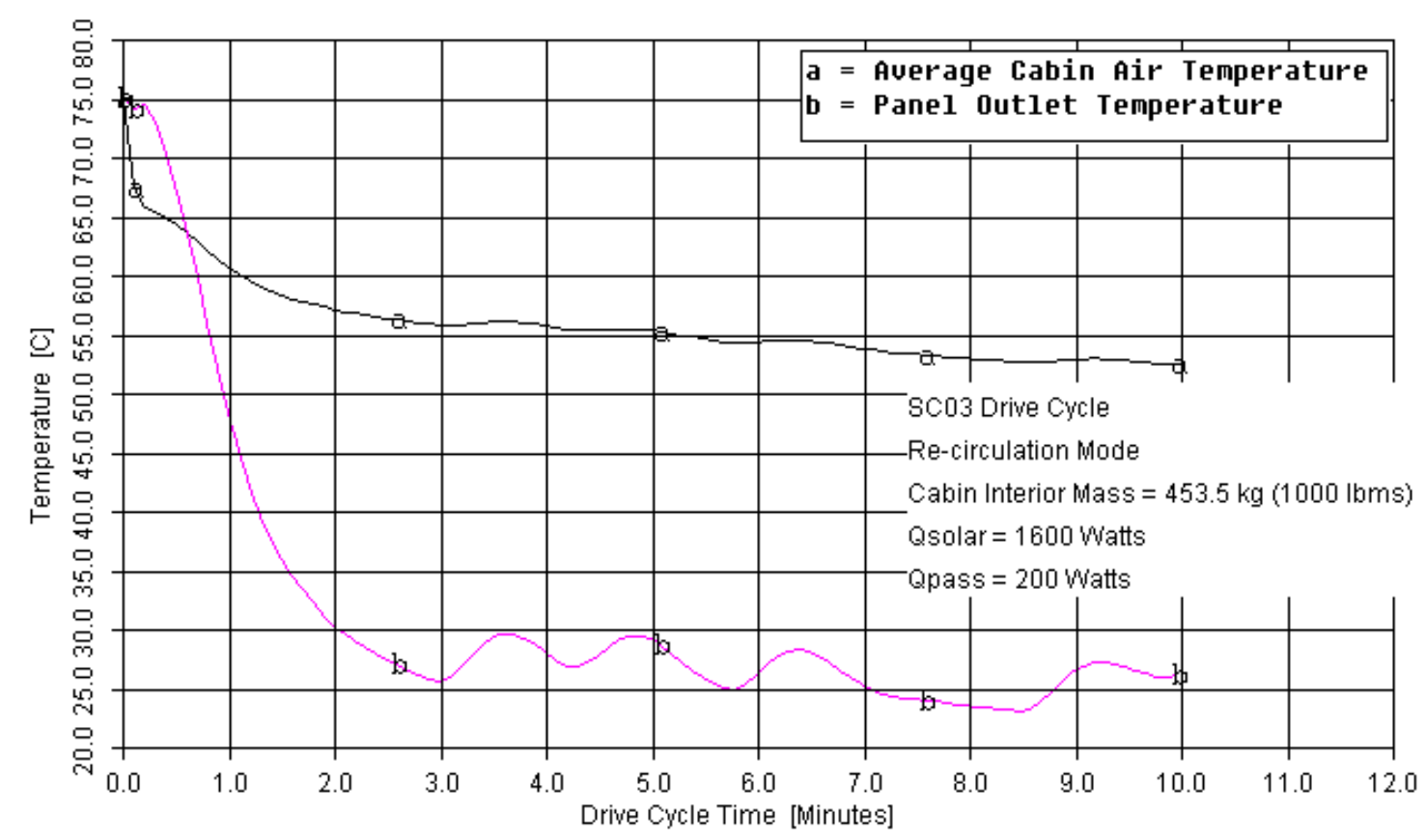

Figure 10 - Typical Cabin Temperature Cool-Down Prediction for an SC03 Drive Cycle after Hot Soak Conditions to $75^{\circ} \mathrm{C}\left(167^{\circ} \mathrm{F}\right)$.

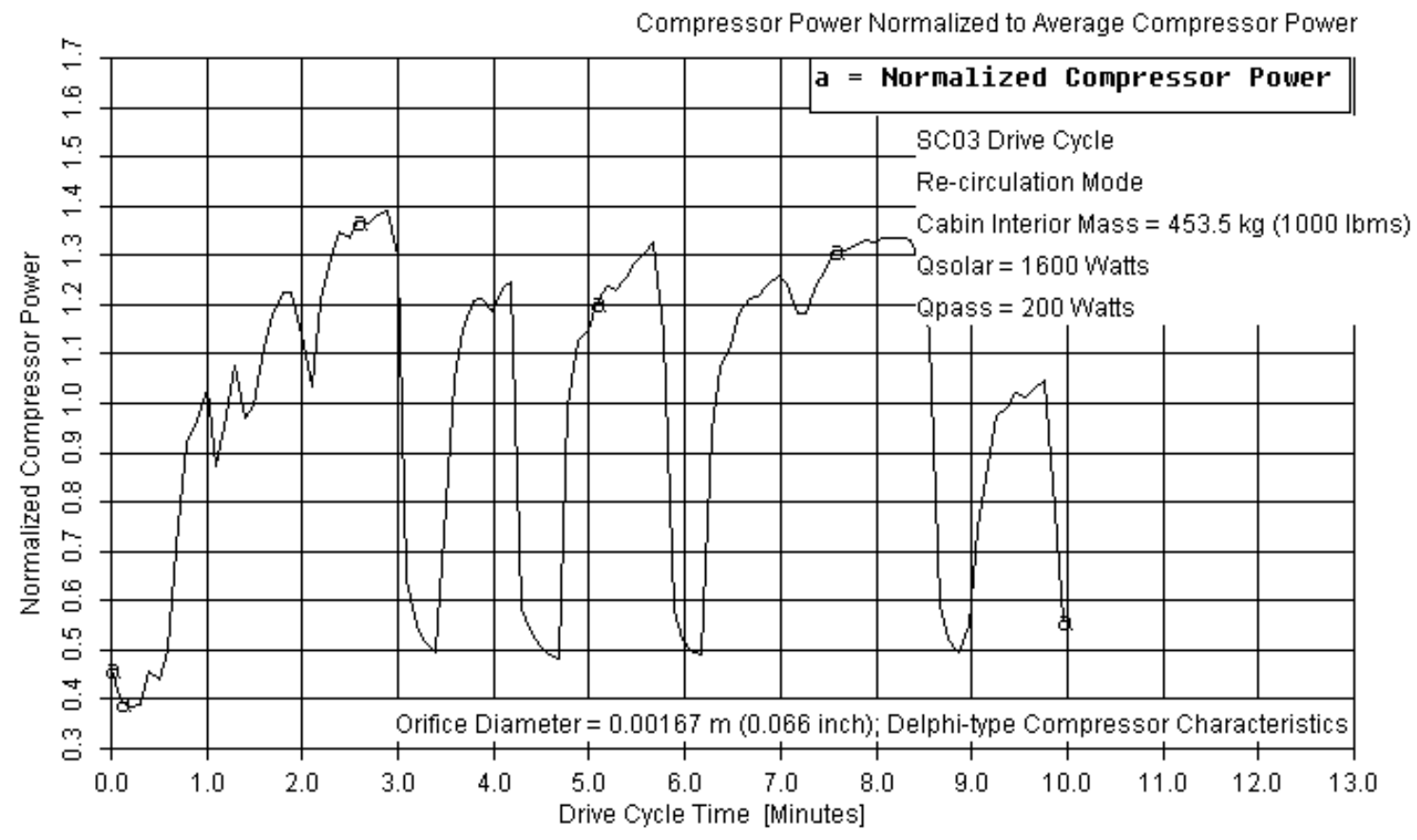

Figure 11 - Compressor Power versus Time Profile for Second Industry-Standard Compressor Characteristics 


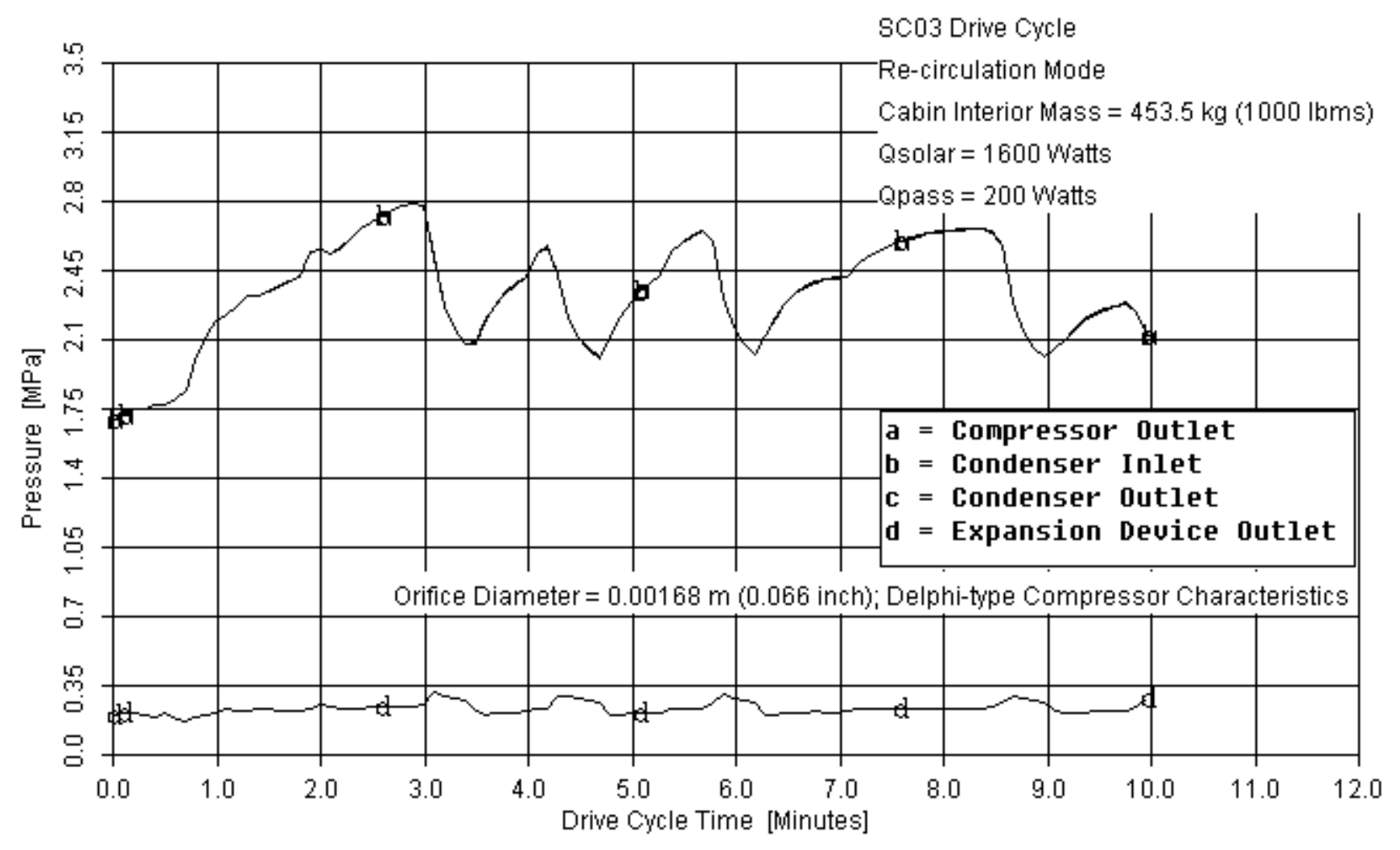

Figure 12 - System Pressure versus Time Profile for Second Industry-Standard Compressor Characteristics

Figure 13 shows a typical condenser flow quality profile predicted at different time points during an SC03 drive cycle. In this figure the condenser is mathematically represented by 20 discrete sections (i.e., flow lumps). Red indicates full vapor conditions, blue represents full liquid conditions, and intermediate colors represent various stages of two-phase flow conditions. Several flow quality/regime profiles at various points in time in the SC03 drive cycle are shown in Figure 13. During the drive cycle the condensation front (red) shifts position in the condenser, which causes flow and heat transfer conditions to vary dynamically. A similar front movement occurs with the evaporation front in the evaporator. Figure 14 displays a typical evaporator flow quality profile prediction during an SC03 drive cycle. The evaporator here is represented by 10 discrete sections (i.e., flow lumps), and red again indicates full vapor conditions, but here blue represents varying degrees of two-phase flow conditions. It is critical to account for and understand this two-phase flow behavior in developing optimized systems. Dynamically variable two-phase flow behavior in both the evaporator and condenser certainly complicates the design and optimization of vehicle $A / C$ systems. 

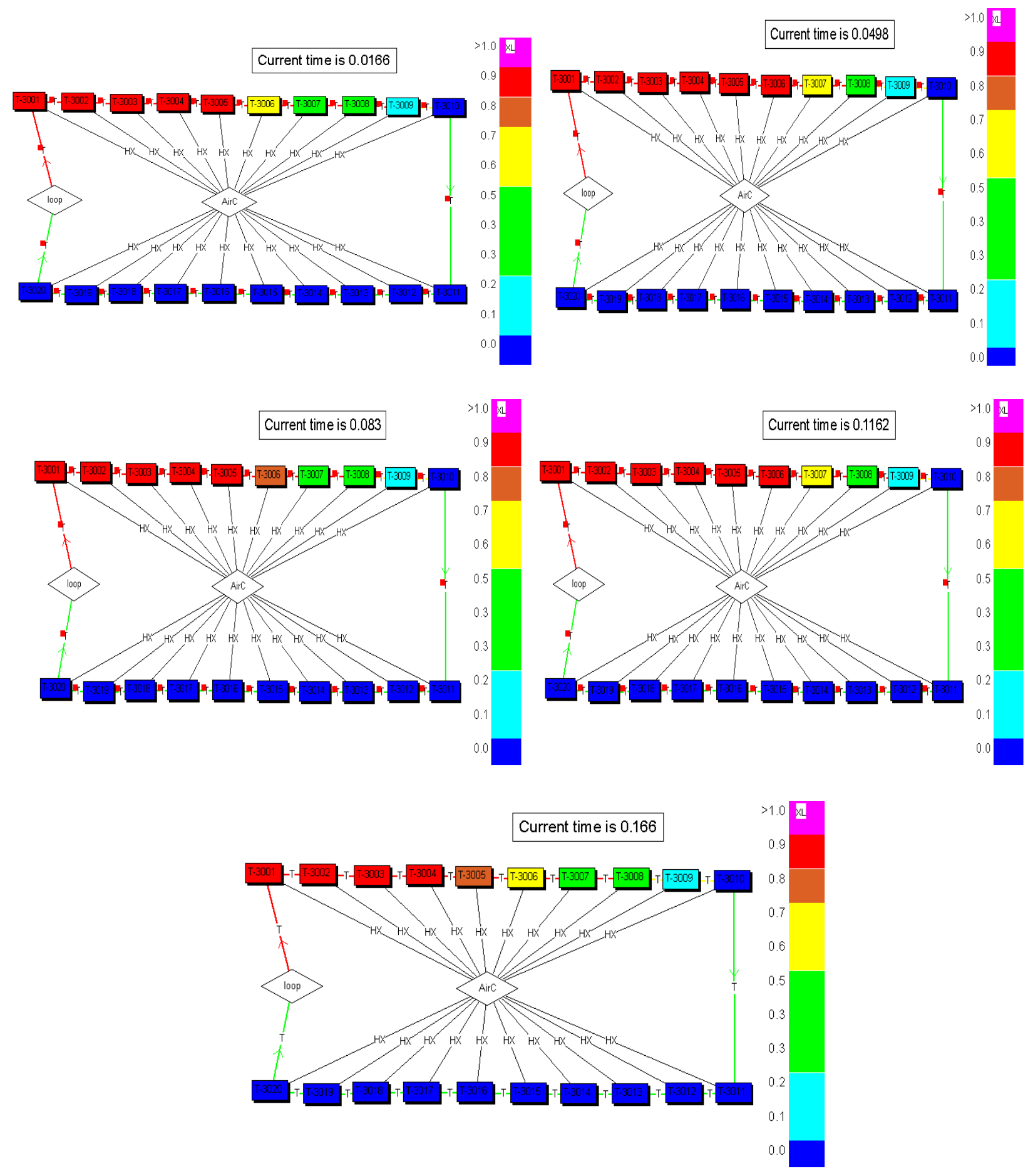

Figure 13 - Transient Flow Quality Profiles in Condenser for an SC03 Drive Cycle (Current Time in Hours) 


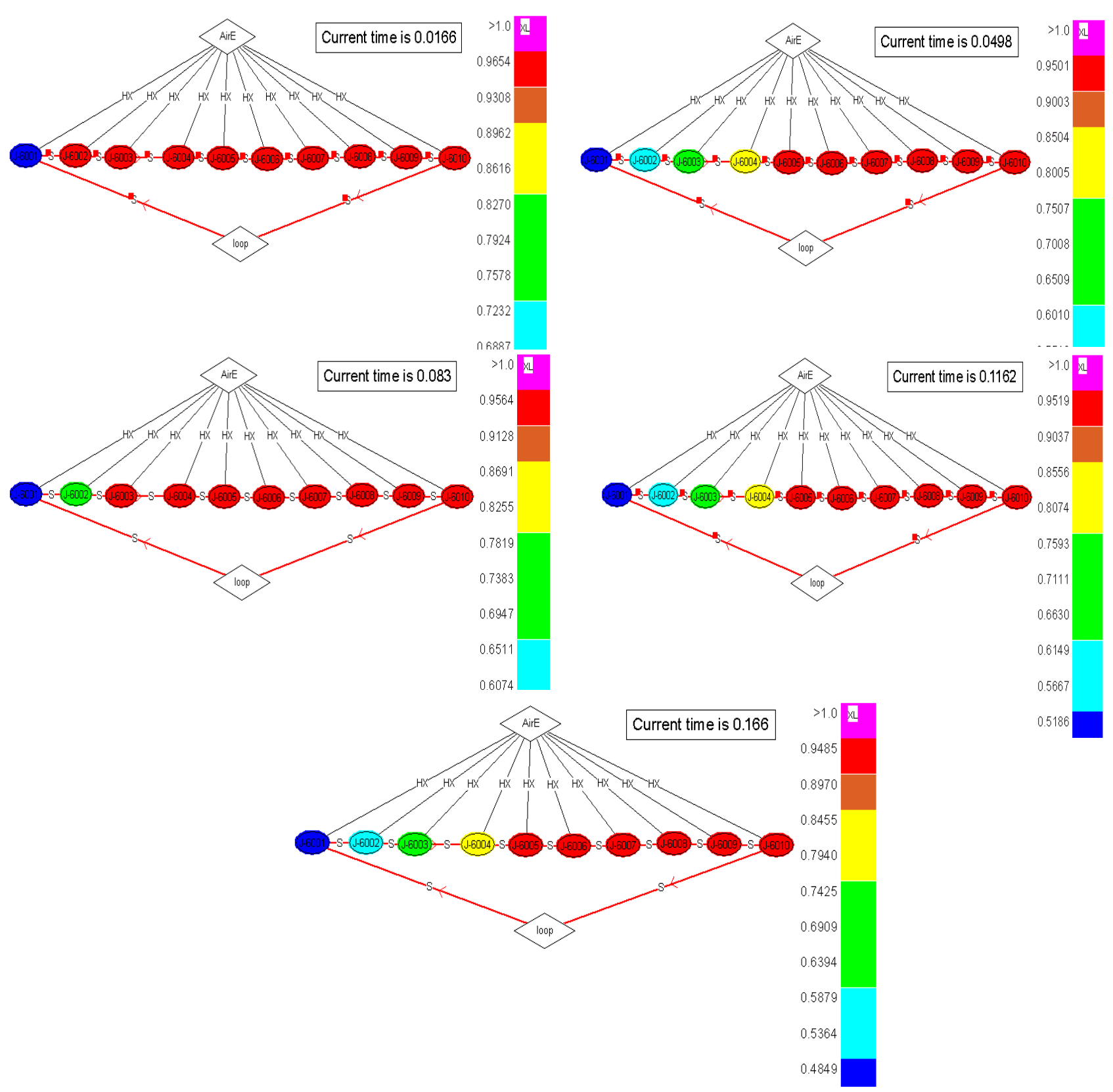

Figure 14 - Transient Flow Quality Profiles in Evaporator for an SC03 Drive Cycle (Current Time in Hours)

While the evaporator and condenser designs certainly affect their internal flow quality profiles and flow regimes, a further complication is that the compressor and expansion device (orifice or TXV) can have major effects on the flow quality and flow regimes within the evaporator and condenser during a typical drive cycle. The compressor performance can change the condensing front movement and the evaporation front movement in the condenser and evaporator, respectively. Similarly, the expansion device can change liquid front positions (blue in Figure 13) in the condenser and the evaporation front movement (red in Figure 14) within the evaporator. In the past, comprehensive analytic tools have not been available to quantify this behavior and determine its impact on the system design and optimization. However, the current SINDA/FLUINT transient A/C model provides a powerful tool to evaluate and understand these component-level effects on system designs prior to system fabrication and testing.

The compressor characteristics can also affect the flow quality profiles in the condenser and the evaporator. Figure 15 shows the flow quality profile at different time points during the $\mathrm{SCO} 3$ drive cycle for the second industrystandard compressor discussed relative to Figures 11 and 12. The condensation front, indicated by the dark red, exhibits different movement with time for this different set of compressor characteristics. Consequently, the flow quality profile for the second compressor is different than that shown in Figure 13, thereby demonstrating how the compressor characteristics can actually affect the flow conditions, such as flow quality and therefore heat transfer, in the condenser. A similar effect occurs in the evaporator where the actual evaporation front movement is impacted by the different compressor characteristics. Figure 16 demonstrates this effect, where the evaporation 
front is indicated again in dark red, with the movement of the dark red lumps being different between Figures 14 and 16.
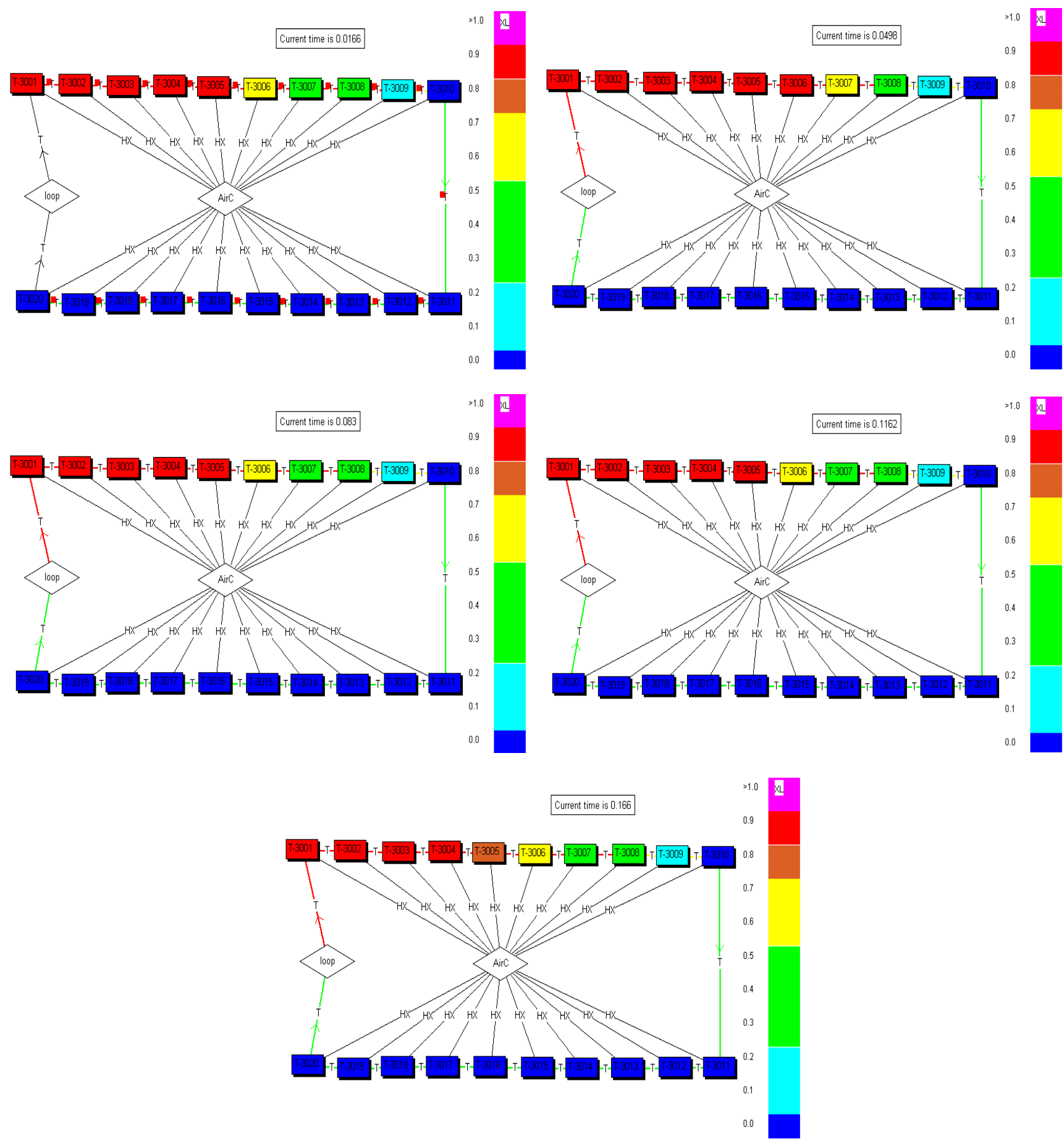

Figure 15 - Transient Flow Quality Profiles in Condenser for Second Industry-Standard Compressor during SC03 Drive Cycle (Current Time in Hours) 

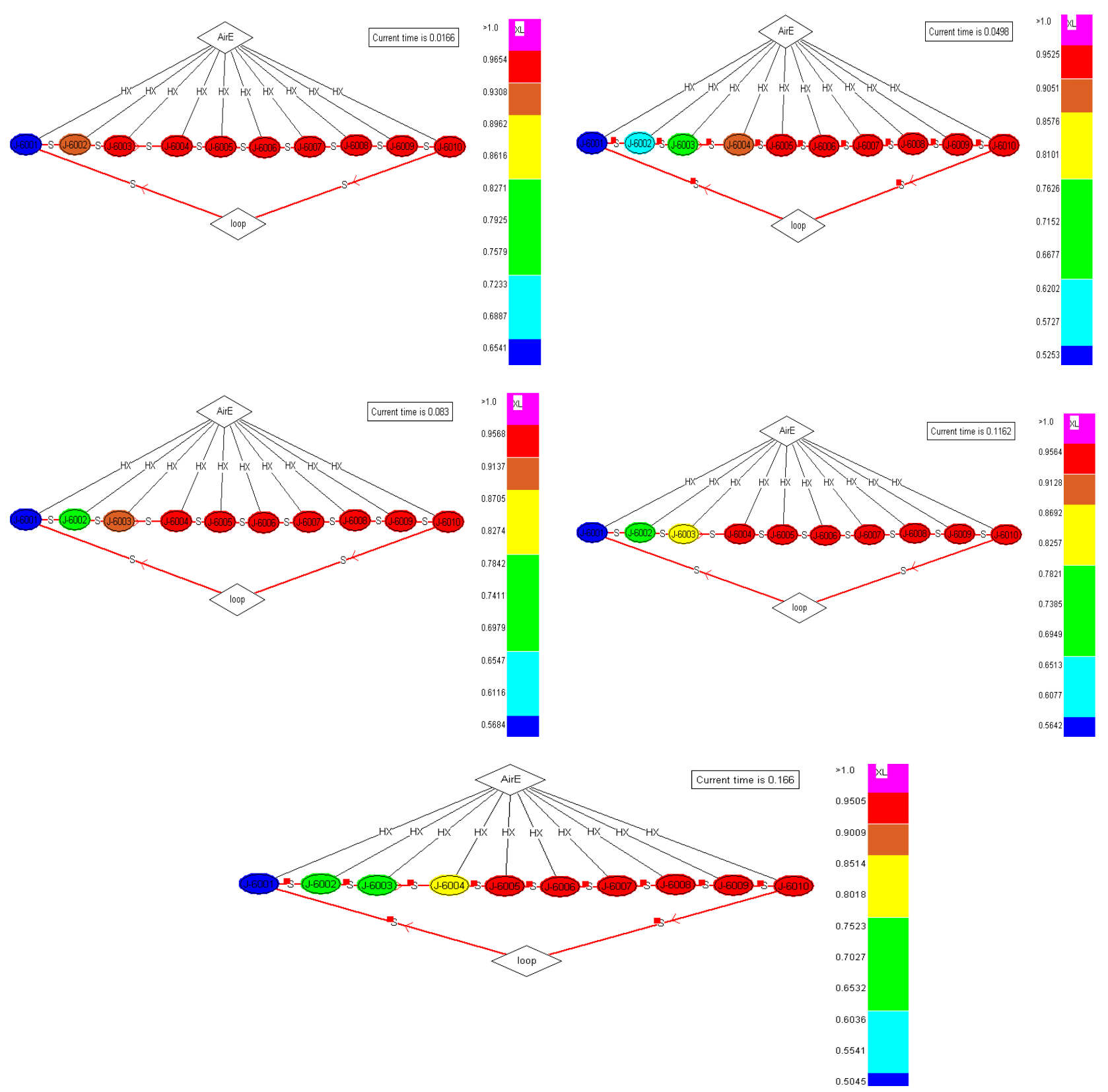

Figure 16 - Transient Flow Quality Profiles in Evaporator for Second Industry-Standard Compressor during SC03 Drive Cycle (Current Time in Hours)

The expansion flow device also affects the flow quality profiles, and therefore heat transfer characteristics, in the condenser and evaporator. Additional system performance studies with this transient $A / C$ system model have demonstrated that liquid front movement in the condenser is affected by the expansion device flow diameter, larger flow diameter moving the liquid front farther downstream in the condenser. Likewise, the vapor front in the evaporator moves farther downstream with a larger expansion device flow diameter.

The final point regarding component effects is that the heat transfer coefficient behavior in both the condenser and evaporator is strongly dependent on position and time during variable-speed drive cycles (i.e., SC03, US06, and other city/highway drive cycles). This effect is generally not accounted for in the steady-state design performance/sizing analyses done by automotive industry $\mathrm{A} / \mathrm{C}$ system designers. Figures 17 and 18 display (heat transfer coefficient* area) versus time at various positions within the vapor, two-phase and liquid sections of the condenser during an SC03 drive cycle simulation. The legend numbering corresponds with the condenser model numbering in Figure 5. Depending on time and position in the condenser, the heat transfer coefficient clearly varies in magnitude by factors of 5-6. This variable behavior is created by the flow rate variation with time and the flow quality variation with time and position shown in Figure 15. Consequently, the heat transfer coefficient is not constant in time or with position as is often assumed in $\mathrm{A} / \mathrm{C}$ system performance/sizing studies in the automotive 
industry. This greatly complicates $\mathrm{A} / \mathrm{C}$ system design and optimization to reduce energy use and engine emissions.

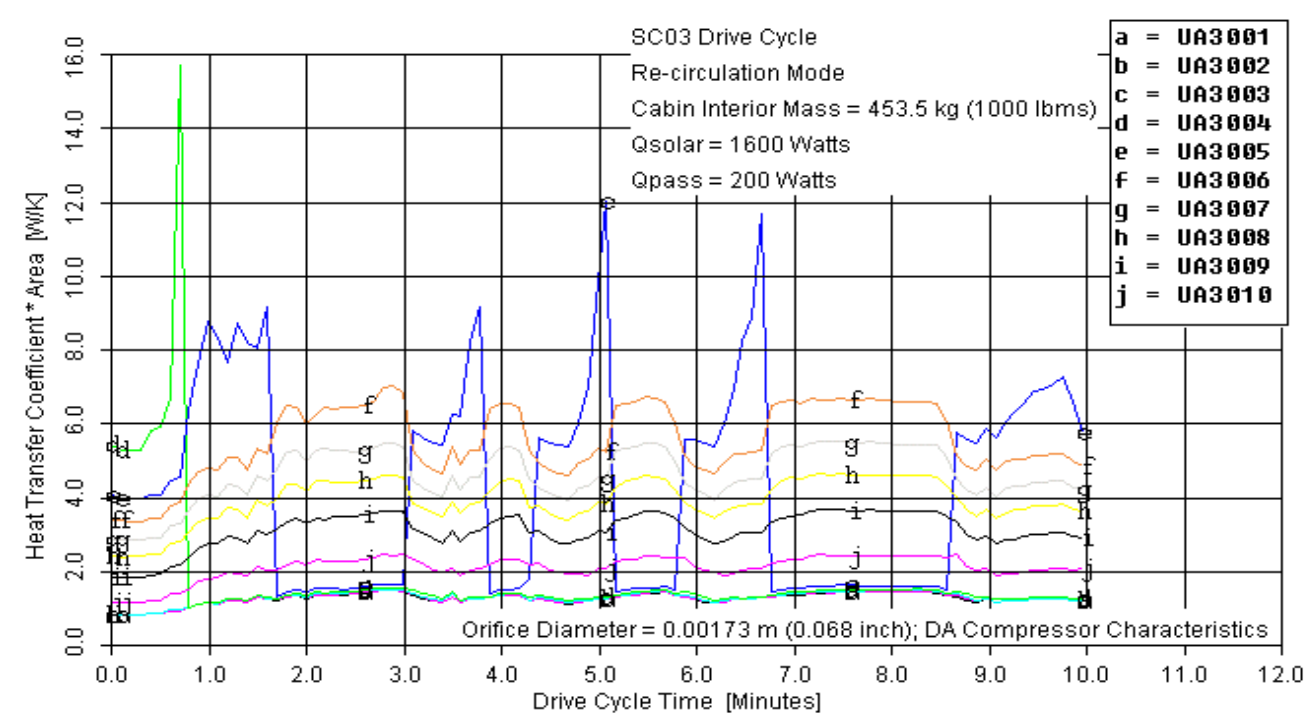

(Heat Transfer Area $=0.003976 \mathrm{~m}^{2}$ )

Figure 17 - Vapor/Two Phase Heat Transfer Coefficient Behavior versus Time/Position in Condenser during SC03 Drive Cycle (a-d is vapor flow, e-j is various degrees of two-phase flow)

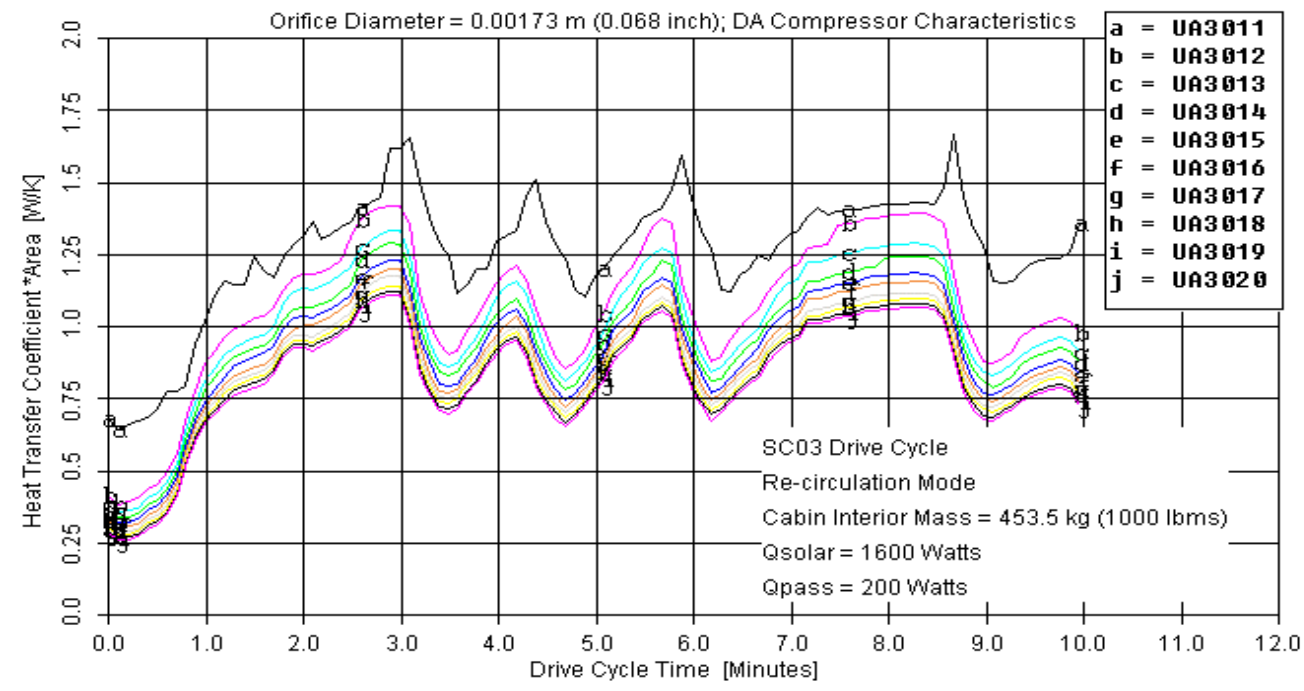

(Heat Transfer Area=0. $003976 \mathrm{~m}^{2}$ )

Figure 18 - Liquid Section Heat Transfer Coefficient Behavior versus Time/Position in Condenser during SC03 Drive Cycle

Similar large variations in heat transfer coefficient with time and position occur in the evaporator. Figures 19 , 20 , and 21 show the predicted heat transfer coefficients as functions of time and position in the evaporator during the SC03 drive cycle. The legend numbering corresponds to the same evaporator model numbering shown in Figure 6. The variation in heat transfer coefficient is again a factor of 5-6 between the evaporator two-phase flow regions in Figure 19 and the evaporator vapor flow regions in Figure 21. In order to truly optimize vehicle A/C systems, one must account for these variations and their impact on the overall system design because of their impact on heat exchanger sizing and performance, and the resulting temperatures and pressures experienced downstream by the compressor. 


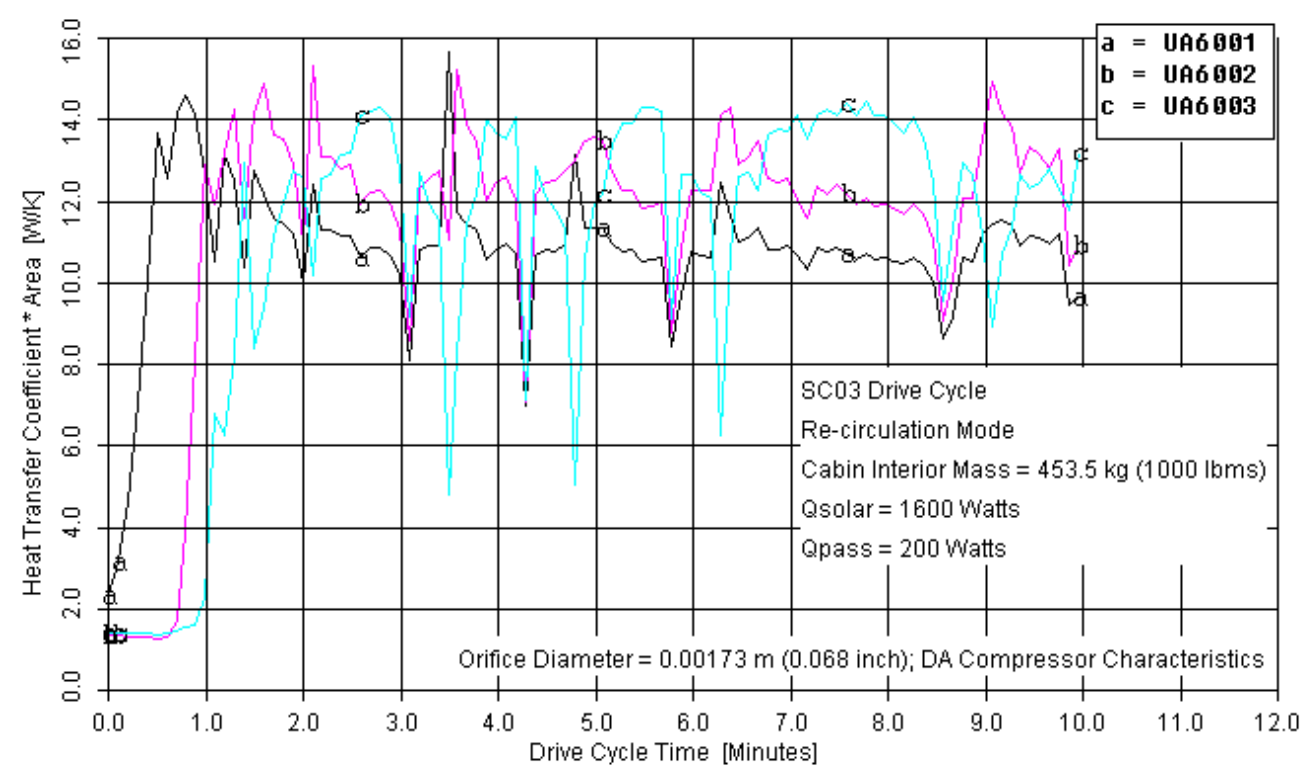

(Heat Transfer Area $=0.000638 \mathrm{~m}^{2}$ )

Figure 19 - Two-Phase Flow Heat Transfer Coefficients versus Time/Position in Evaporator during SC03 Drive Cycle

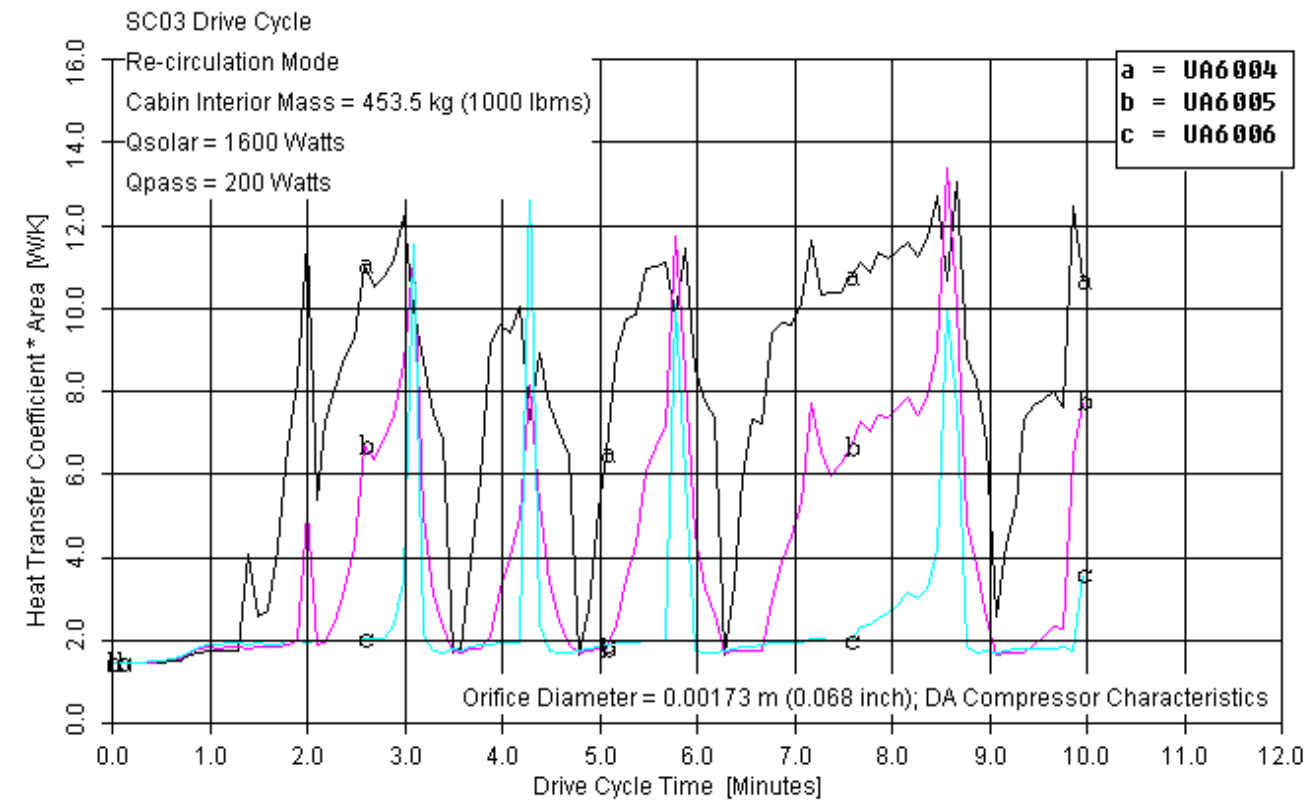

(Heat Transfer Area $=0.000638 \mathrm{~m}^{2}$ )

Figure 20 - Two-Phase/Vapor Heat Transfer Coefficients versus Time/Position in Evaporator during SC03 Drive Cycle 


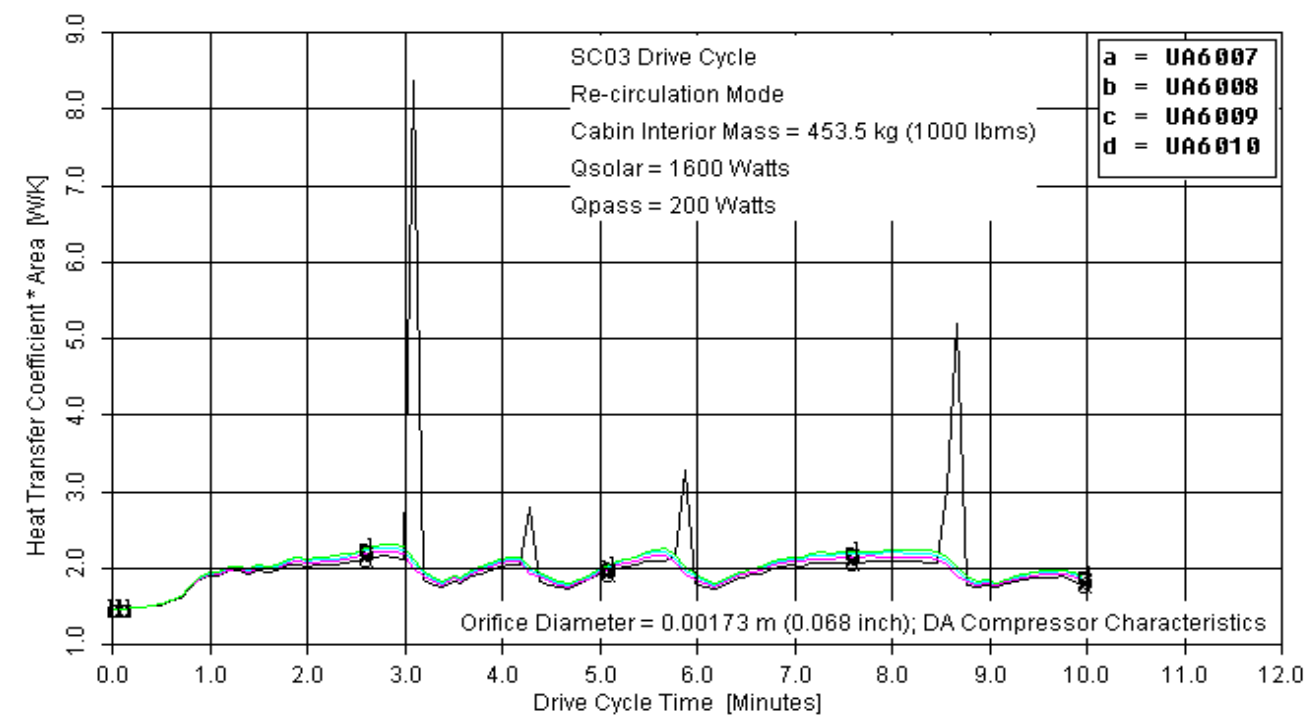

(Heat Transfer Area $=0.000638 \mathrm{~m}^{2}$ )

Figure 21 - Vapor Flow Heat Transfer Coefficients versus Time/Position in Evaporator during SC03 Drive Cycle

\subsection{SYSTEM OPTIMIZATION STUDIES}

Optimizing the $A / C$ system design can significantly reduce the mass and volume of current $A / C$ systems in various vehicles, and impact the $A / C$ system control strategy, in satisfying cabin thermal comfort requirements. However, truly optimizing the $\mathrm{A} / \mathrm{C}$ system design is complicated by the transient nature of the system performance and its inherent coupling to cabin thermal conditions (i.e., heat loads, air temperatures, vent configurations, etc.). Optimizing these systems requires one to consider a new "transient design" perspective. The A/C system pressures, temperatures, and condenser and evaporator flow conditions are all time-dependent. They are controlled by transient compressor speed, refrigerant and airflow rates, and vehicle thermal loads. Refrigerant and airflow rates are, in turn, determined by vehicle velocity and compressor speed, which is a function of engine speed in mechanically driven compressor systems. Compressor power, being typically proportional to compressor speed cubed, can be highly variable during the SC03 or any other drive cycle. Consequently, the important thermal design parameters, such as the evaporator heat load, compressor power, and COP, become timeaveraged design parameters given by equations:

$$
\begin{aligned}
& \hat{q}=\frac{1}{t_{2}-t_{1}} \int_{t_{1}}^{t_{2}} q(t) d t \\
& \hat{P}=\frac{1}{t_{2}-t_{1}} \int_{t_{1}}^{t_{2}} P(t) d t \\
& \hat{\eta}=\frac{\hat{q}}{\hat{P}}
\end{aligned}
$$

These time-averaged quantities are what one typically measures in $\mathrm{A} / \mathrm{C}$ system bench-top or vehicle-level testing and can therefore be correlated with transient model predictions. Additional time-dependent design parameters must be considered such as:

$p_{H}(t)$ - time-dependent pressure profiles on the high-pressure side of the system

$p_{L}(t)$ - time-dependent pressure profiles on the low-pressure side of the system 
$h_{C}(l, t)$ - time- and position-dependent heat transfer coefficients in the condenser

$h_{E}(l, t)$ - time- and position-dependent heat transfer coefficients in the evaporator

$X_{C}(l, t)$ - time- and position-dependent flow quality in the condenser

$X_{E}(l, t)$ - time- and position-dependent flow quality in the evaporator

In some cases, time-integrated quantities of these parameters may be important in the system design and optimization. Our results to date have shown that indeed there exist optimum time-dependent profiles $\left[p_{H}(t)\right]_{o p t}$ and $\left[\mathrm{X}_{c}(\mathrm{l}, \mathrm{t})\right]_{\mathrm{opt}}$ that maximize system performance (i.e., maximizing COP for minimum energy use) in a given drive cycle. Of course, the same design concerns related to system cost and weight still exist and must ultimately be accounted for in the design optimization.

In the most rigorous sense, another complicating factor in predicting the transient performance of a vehicle $\mathrm{A} / \mathrm{C}$ system is accurately modeling refrigerant inertia during compressor accelerations and decelerations. The SINDA/FLUINT A/C system model automatically calculates and tracks fluid inertia within its lump/path formulation and accounts for inertial effects on fluid behavior (within its equation set). Furthermore, the thermal mass, and therefore thermal energy storage potential, associated with each system component also must be simulated in all component and system energy balances. One then has to be concerned with time-average thermal energy storage for each $\mathrm{i}^{\text {th }}$ component given by:

$\frac{1}{t_{2}-t_{1}} \int_{t_{1}}^{t_{2}} m_{i} \cdot \bar{C}_{p, i} \cdot\left(\frac{d T}{d t}\right)_{i} d t$

which complicates system and component energy balances. Accurately accounting for each of the timedependent quantities in a full $\mathrm{A} / \mathrm{C}$ system transient analysis makes it imperative that a high-level system analysis tool, such as SINDA/FLUINT, be used in any $A / C$ system design optimization studies based on transient performance.

Additional challenges exist because $\mathrm{A} / \mathrm{C}$ system design optimizations can be performed using various systemlevel assumptions. Among these one can assume:

1) Constant system refrigerant mass,

2) Constant system initial pressure,

3) Various vehicle drive cycle conditions, or

4) Constant/variable vehicle solar thermal loads.

Care must be taken in $\mathrm{A} / \mathrm{C}$ system optimization work because the assumption made and the specific value assumed; for example, for initial system pressure or solar thermal load, can affect the final solution.

SC03 DRIVE CYCLE RESULTS - Optimization studies were initiated by performing a dual-variable optimization maximizing system COP, defined in Eq. 5, to determine the combined effect of transport line diameter and condenser tube diameter on the system design. The integrated A/C system/cabin thermal model was used to investigate a range of condenser tube diameters for constant system refrigerant mass $(2.15 \mathrm{lbms})$ assuming an SC03 drive cycle, a cabin external solar load of 1600 Watts, a cabin passenger heat load of 200 Watts, and an initial internal cabin temperature of $75{ }^{\circ} \mathrm{C}\left(167^{\circ} \mathrm{F}\right)$. The integrated $\mathrm{A} / \mathrm{C}$ system/cabin thermal model in SINDA/FLUINT investigated a range of transport line diameter/condenser tube diameter combinations for the same constant refrigerant mass. Figure 22 shows the results of this dual-variable system optimization for SC03 drive cycle conditions in a three-dimensional plot of the COP versus transport line and condenser tube diameter, as determined during several optimization searches performed by SINDA/FLUINT. This optimization was performed within SINDA/FLUINT, accounting for all the two-phase heat transfer /pressure drop effects and flow 
transition effects in the condenser and evaporator. In any system optimization it is important to perform a comprehensive search of the variable design space to locate the optimum solution. Figure 22 shows the results of several different runs starting at various initial guesses. In general, the arrows in the Figure 22 plot show the various initial guesses for these parameters and general direction of solution as the optimization progresses to a solution. The optimal solution maximizing system COP was found to be a transport line diameter of approximately $2.29 \mathrm{~cm}(0.90 \mathrm{inch})$ and a condenser tube diameter of approximately $0.254 \mathrm{~cm}(0.10 \mathrm{inch})$. The optimal solution shown in Figure 22 demonstrates the design performance benefit of expending available pressure drop in the condenser, and thereby enhancing heat transfer in the condenser, and minimizing pressure drop in the transport lines between the system components. These optimum results are quite different from current vehicle $A / C$ systems, transport line diameters are generally about 0.889-1.27 cm (0.35-0.5 inch) and condenser tube diameters of $0.508 \mathrm{~cm}$ (0.2 inch) are common. Again, this optimization was performed with SINDA/FLUINT, simulating all the two-phase heat transfer/pressure drop effects and flow transition effects in the condenser and evaporator.

One important point is that the optimal selection for condenser tube diameter is strongly affected by the dualvariable optimization in Figure 22 versus single-variable optimizations. A much different optimal condenser tube diameter will be discovered when only a single variable (i.e., condenser tube diameter) is optimized without any impacts from other design parameters. This demonstrates the strong interrelationships and effects between various system design parameters in the $A / C$ system. A full system, multiple-variable optimization is required to accurately optimize system performance, whether maximizing system COP or optimizing other system performance parameters.

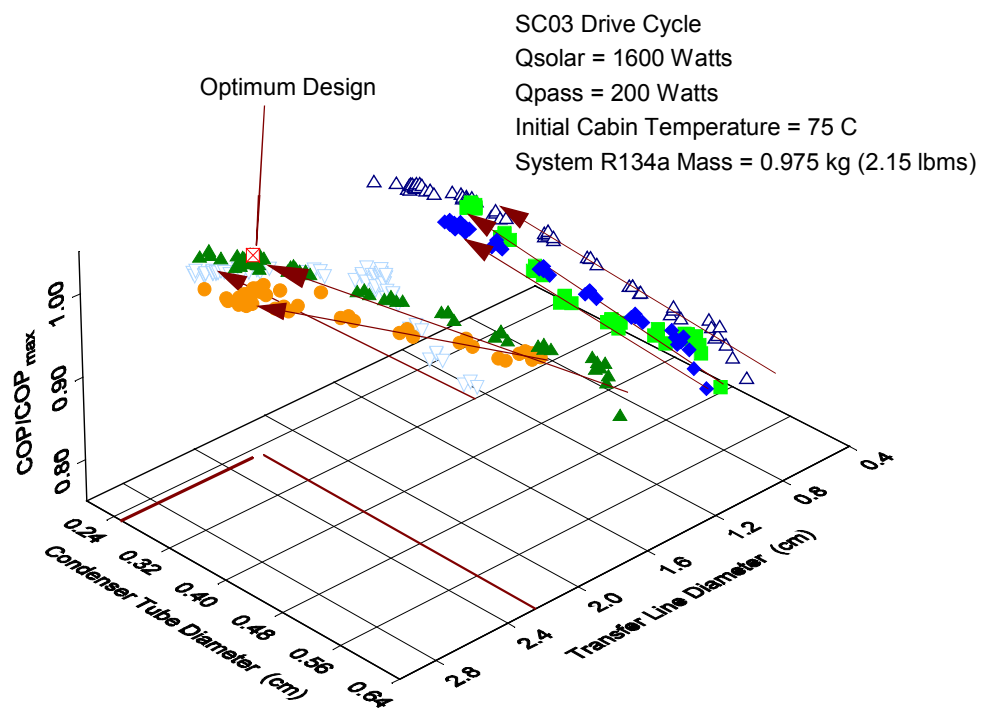

Figure 22 - Optimum Dual Variable Solution to Maximize System COP - Optimum Transport Line Diameter and Condenser Tube Diameter

Additional optimization studies were performed assuming a somewhat more realistic constant initial pressure at the start of the drive cycle and slightly different compressor characteristics. In these studies the initial system pressure was $1.689 \mathrm{MPa}(245 \mathrm{psi})$. Figure 23 displays the latest results of this optimization study, with three different runs performed starting at three separate initial starting points. Arrows in Figure 23 again show the initial guesses for the design parameters and general direction of solution during the optimization. A different optimal solution was found as a result of changing the system assumption to constant initial pressure, rather than constant refrigerant mass, and using slightly different compressor characteristics. This solution is still tending toward larger transfer line diameters (approximately $1.29 \mathrm{~cm}$ or $0.51 \mathrm{inch}$ ), but it is also indicating larger condenser tube diameters (approximately $0.610 \mathrm{~cm}$ or 0.24 inch) than the previous optimization using constant refrigerant mass. This work emphasizes the need to optimize the $\mathrm{A} / \mathrm{C}$ system as a system, even slight changes in one critical component like the compressor can lead to a much different optimum system design. Certainly taking one off-theshelf component and combining it with other off-the-shelf components, without a true system design approach and optimization, will not produce the optimum system performance. 
Multiple variable optimization studies were also extended to simultaneous optimizations of three design parameters, expansion device diameter, transfer line diameter, and condenser tube diameter, over the SC03 drive cycle. The initial system pressure assumption of $1.689 \mathrm{MPa}(245 \mathrm{psi})$ was maintained, along with all the other system conditions depicted in Figures 22 and 23. Previous dual-variable optimization work discussed earlier was problematic and tedious because, during the optimization process, it is actually quite easy to define and attempt to analyze a nonrealistic design. This quickly leads to computational stability problems because it is just as impossible to analyze a nonrealistic system design as it is to fabricate and test such a design. Although the optimization problem becomes more complex and computationally intense with triple-variable or quadruplevariable optimization, this work found that this does not necessarily lead to more computational instabilities. In fact, simultaneously optimizing the expansion device diameter, transfer line diameter, and condenser tube diameter was surprisingly stable, most likely due to the added degree of freedom in the system.

Increase Model Fidelity / DA Compressor / Pinit = 1.689 MPa (245 psi)

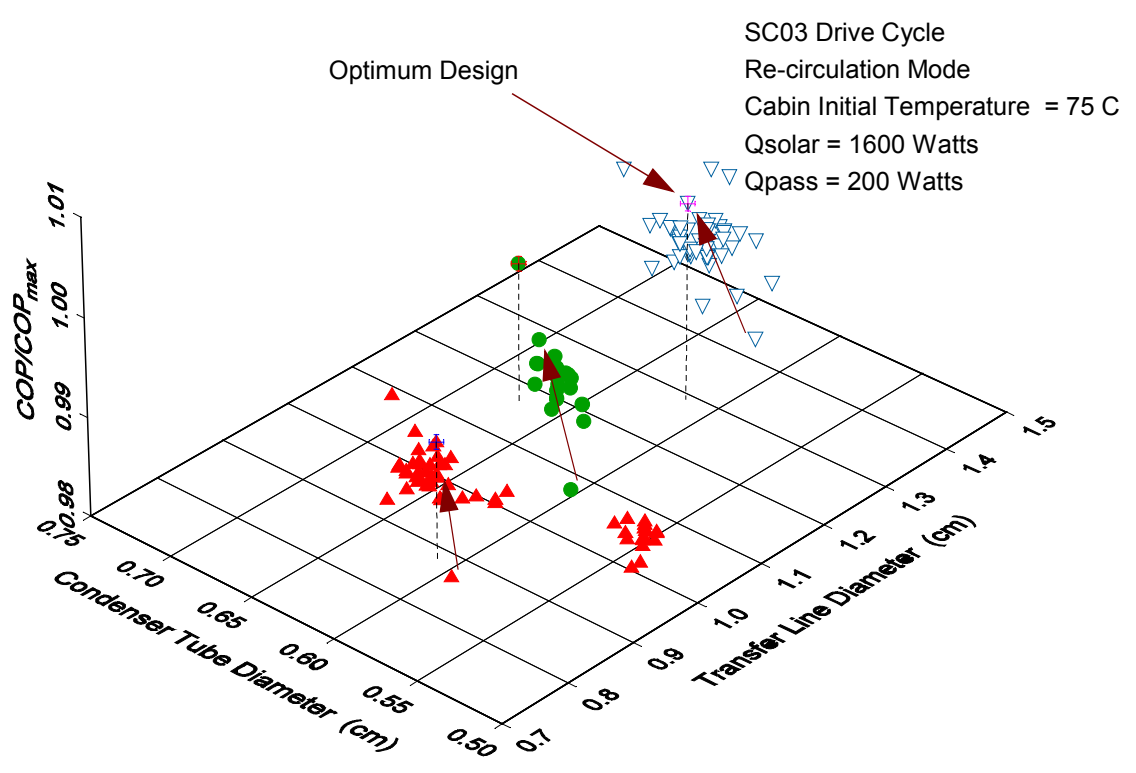

Figure 23 - Optimum Transfer Line Diameter and Condenser Tube Diameter to Maximize System COP (Constant Initial System Pressure)

As before, the system optimization runs started from multiple initial starting points with a constant initial pressure of $1.689 \mathrm{MPa}(245 \mathrm{psi})$. Table 1 displays the results of five separate tri-variable optimization runs. The first column is the optimization loop count and tells how many solution iterations were required to achieve a solution and check for convergence. The next three columns show the design parameter values at each search point. The next column shows the value of the objective function, in this case the average COP over the SC03 driving cycle. The last column is simply the COP ratio relative to the maximum.

Among the five runs in Table 1, Runs 2 and 5 determined two potential solutions that maximized COP within this group. In one case (Run 2), a relatively large expansion device diameter $(0.221 \mathrm{~cm}$ or 0.0869 inch), a relatively large transfer diameter $(2.02 \mathrm{~cm}$ or $0.795 \mathrm{inch})$, and a condenser tube diameter of $0.587 \mathrm{~cm}$ or 0.231 inch produced the optimal performance. In Run 5 a much smaller expansion device diameter and smaller condenser tube diameter, with roughly the same transfer line diameter $(1.91 \mathrm{~cm}$ or $0.752 \mathrm{inch})$, produced the optimal result. Runs 1, 3 and 4 sachieved intermediate solutions representing local maximums that could go no further in the optimization process because of convergence criteria limitations. It is quite common in multivariable optimization of nonlinear problems to discover multiple solutions that satisfy, either maximizing or minimizing, the objective function goal. The solutions in Runs 2 and 5 correspond to quite different optimum system solutions that one would evaluate further. At this point, additional design information would have to be considered (possibly system cost, weight, etc.) to differentiate the two to one system-level solution. One could develop a different objective function involving additional design objectives and re-optimize the system design to quantifiably distinguish between the two solutions. 
Table 1 - Optimum Expansion Device Diameter, Transfer Line Diameter, and Condenser Line Diameter Maximizing COP during the SC03 Drive Cycle (Optimums in Red)

\begin{tabular}{|c|c|c|c|c|c|}
\hline $\begin{array}{c}\text { Run } \\
\# 1 \\
\text { Loop } \\
\# \\
\end{array}$ & $\begin{array}{c}\text { Expansion } \\
\text { Device } \\
\text { Diameter } \\
\text { (cm) }\end{array}$ & $\begin{array}{l}\text { Transfer } \\
\text { Line } \\
\text { Diameter } \\
\text { (cm) }\end{array}$ & $\begin{array}{c}\text { Condenser } \\
\text { Line } \\
\text { Diameter } \\
(\mathrm{cm}) \\
\end{array}$ & $\begin{array}{c}\text { Average } \\
\text { COP }\end{array}$ & $\begin{array}{l}\text { Normalized } \\
\text { COP }\end{array}$ \\
\hline 1 & .1676 & 1.27 & .5405 & 1.087 & .9811 \\
\hline 67 & 2190 & 2.0034 & .6872 & 1.108 & 1 \\
\hline 70 & .2527 & 2.1622 & .6969 & 1.107 & .9998 \\
\hline $\begin{array}{c}\text { Run } \\
\# 2 \\
\text { Loop } \\
\#\end{array}$ & $\begin{array}{l}\text { Expansion } \\
\text { device } \\
\text { Diameter } \\
(\mathrm{cm})\end{array}$ & $\begin{array}{l}\text { Transfer } \\
\text { Line } \\
\text { Diameter } \\
(\mathrm{cm})\end{array}$ & $\begin{array}{c}\text { Condenser } \\
\text { Line } \\
\text { Diameter } \\
(\mathrm{cm})\end{array}$ & $\begin{array}{c}\text { Average } \\
\text { COP }\end{array}$ & $\begin{array}{l}\text { Normalized } \\
\text { COP }\end{array}$ \\
\hline 1 & .1778 & 1.143 & .5606 & 1.144 & .9825 \\
\hline 99 & .2207 & 2.020 & .5856 & 1.164 & 1 \\
\hline $\begin{array}{c}\text { Run } \\
\# 3^{\star *} \\
\text { Loop } \\
\# \\
\end{array}$ & $\begin{array}{c}\text { Expansion } \\
\text { Device } \\
\text { Diameter } \\
(\mathrm{cm})\end{array}$ & $\begin{array}{c}\text { Transfer } \\
\text { Line } \\
\text { Diameter } \\
(\mathrm{cm})\end{array}$ & $\begin{array}{l}\text { Condenser } \\
\text { Line } \\
\text { Diameter } \\
(\mathrm{cm})\end{array}$ & $\begin{array}{c}\text { Average } \\
\text { COP }\end{array}$ & $\begin{array}{c}\text { Normalized } \\
\text { COP }\end{array}$ \\
\hline 1 & .1778 & 1.1430 & .5606 & 1.141 & .9934 \\
\hline 26 & .1876 & 1.1932 & .5819 & 1.149 & 1 \\
\hline 38 & .1876 & 1.1712 & .5815 & 1.149 & .9998 \\
\hline
\end{tabular}

\begin{tabular}{|c|c|c|c|c|l|}
\hline $\begin{array}{c}\text { Run } \\
\text { Lu } \\
\#\end{array}$ & $\begin{array}{c}\text { Expansion } \\
\text { Device } \\
\text { Diameter } \\
(\mathrm{cm})\end{array}$ & $\begin{array}{c}\text { Transfer } \\
\text { Line } \\
\text { Diameter } \\
(\mathrm{cm})\end{array}$ & $\begin{array}{c}\text { Condenser } \\
\text { Line } \\
\text { Diameter } \\
(\mathrm{cm})\end{array}$ & $\begin{array}{c}\text { Average } \\
\text { COP }\end{array}$ & $\begin{array}{c}\text { Normalized } \\
\text { COP }\end{array}$ \\
\hline 1 & 0.1778 & 1.1430 & 0.5606 & 1.143 & 0.9949 \\
\hline 20 & 0.1813 & 1.1901 & 0.5977 & 1.149 & 0.9998 \\
\hline 92 & 0.1787 & 1.2457 & 0.5362 & 1.149 & 1 \\
\hline $\begin{array}{c}\text { Run } \\
\# 5 \\
\text { Loop } \\
\#\end{array}$ & $\begin{array}{c}\text { Expansion } \\
\text { Device } \\
\text { Diameter } \\
(\mathrm{cm})\end{array}$ & $\begin{array}{c}\text { Transfer } \\
\text { Line } \\
\text { Diameter } \\
(\mathrm{cm})\end{array}$ & $\begin{array}{c}\text { Condenser } \\
\text { Line } \\
\text { Diameter } \\
\text { (cm) }\end{array}$ & $\begin{array}{c}\text { Average } \\
\text { COP }\end{array}$ & $\begin{array}{c}\text { Normalized } \\
\text { COP }\end{array}$ \\
\hline 1 & .1778 & 1.2192 & 0.5563 & 1.143 & 0.982 \\
\hline 86 & .1473 & 1.9963 & 0.2842 & 1.164 & 0.9998 \\
\hline 137 & .1489 & 1.9111 & 0.3796 & 1.164 & 1 \\
\hline
\end{tabular}

The system optimization work has also been extended to a very interesting quadruple-variable optimization in which compressor displacement, expansion device diameter, transfer line diameter, and condenser tube diameter were optimized simultaneously. This optimization was intended to investigate the hypothesis that interrelationships between the compressor displacement and expansion device performance could lead to higher performing designs because of their combined impact on system pressure profiles and compressor pressure ratio. Table 2 shows the starting point designs and the optimum design results from this quadruple-variable optimization for three different initial system pressures (i.e., $1.627 \mathrm{MPa}$ or $236 \mathrm{psi}, 1.689 \mathrm{MPa}$ or $245 \mathrm{psi}$, and $1.758 \mathrm{MPa}$ or $255 \mathrm{psi}$ ) during the $\mathrm{SCO} 3$ drive cycle. The optimum design points are highlighted in red. The optimum design point was slightly different for the three pressure cases, with the optimum expansion device diameter decreasing and evaporator thermal load at optimum design increasing as initial system pressure increases. The optimum transfer line diameter results show a minimum in these three cases at an initial system pressure of $1.689 \mathrm{MPa}$ (245 psi). The optimum condenser tube diameter is exhibiting a maximum in these three cases at an initial system pressure of $1.689 \mathrm{MPa}(245 \mathrm{psi})$. This is interesting behavior and it will have to be investigated further in future work to confirm and better understand it and its causes. 
In all three optimization runs, the optimum system design increased the system COP from about 1.14 to about 1.61 , and decreased $\mathrm{A} / \mathrm{C}$ compressor power approximately $35 \%, 37 \%$, and $39 \%$ for the three optimization runs, respectively. Therefore, an optimum combination of compressor displacement, expansion device diameter, transfer line diameter, and condenser tube diameter exists that allows the $\mathrm{A} / \mathrm{C}$ system to operate at its maximum $\mathrm{COP}$ over the $\mathrm{SC0} 3$ drive cycle. It is quite noteworthy that the compressor power savings shown in the three optimization runs would translate into a fuel economy increase of 1.8-3.5 miles per gallon in today's vehicles.

Upon further investigating the performance increases in Table 2, straightforward mass conservation within the A/C system, particularly on the high-pressure side of the system, leads to a relationship between the compressor displacement (volume), the expansion device flow diameter and the pressure ratio across the compressor:

$$
\frac{V_{d i s p}}{A_{\exp }} \propto f\left[p_{H}(t) / p_{L}(t)\right]
$$

Furthermore, an optimum compressor displacement/expansion flow area ratio exists that is related to optimum pressure profile conditions that maximizes the A/C system COP:

$$
\left[\frac{V_{\text {disp }}}{A_{\text {exp }}}\right]_{\text {optimum }} \propto f\left[\left[p_{H}(t)\right]_{\text {opt }} /\left[p_{L}(t)\right]_{\text {opt }}\right]
$$

When examining the high-side pressure profiles, $p_{H}(t)$, for the three optimization runs shown in Table 2, it was clear an optimum, $\left[\mathrm{p}_{\mathrm{H}}(\mathrm{t})\right]_{\mathrm{opt}}$, exists and is related to the maximum system COP conditions. Figure 24 shows the pressure profiles, $p_{H}(t)$, for all the analyses performed for the $1.689 \mathrm{MPa}(245 \mathrm{psi})$ initial pressure case in Table 2. The Figure 24 pressure data show a distinct clustering (i.e., distinct darker pressure profile) about the "preferred optimum" pressure profile once the SINDA/FLUINT A/C model determined and focused on the optimum performance design. This preferred optimum pressure profile has distinctly much smaller pressure fluctuations than the other off-optimum pressure profiles in Figure 24. The optimum design is therefore one in which pressure fluctuations, and the accompanying mass flow rate accelerations/decelerations, are minimized. The preferred optimum pressure profile and clearly related optimum compressor displacement and expansion device flow area forms the basis for believing that variable displacement compressors, variable orifice valves (VOVs) and electricaldriven compressors can significantly improve current $A / C$ system performance, thereby reducing vehicle fuel consumption and emissions. There is undoubtedly also an optimum low-pressure profile, $\left[p_{L}(t)\right]_{\text {opt }}$, in Figure 24 , but variations from optimum are too small to detect and its impact on performance is smaller than the high-pressure profile, $\left[p_{H}(t)\right]_{o p t}$. Future work will concentrate on identifying and quantifying the opportunities to improve vehicle $\mathrm{A} / \mathrm{C}$ systems by using these system components, and system-level, fundamentals-based optimized designs evolved from integrated vehicle systems analysis. 
Table 2 - Quadruple-Variable Optimization Results for SC03 Drive Cycle Conditions (Simultaneous Optimization of Compressor Displacement, Expansion Device Diameter, Transfer Line Diameter, Condenser Tube Diameter)

\begin{tabular}{||ccccccccc||}
\hline $\begin{array}{c}\text { Solution } \\
\text { Loop } \\
\text { Count }\end{array}$ & $\begin{array}{c}\text { Expansion } \\
\text { Device } \\
\text { Diameter } \\
(\mathrm{cm})\end{array}$ & $\begin{array}{c}\text { Transfer } \\
\text { Liame } \\
\text { Diamer } \\
(\mathrm{cm})\end{array}$ & $\begin{array}{c}\text { Compressor } \\
\text { Displacement }\end{array}$ & $\begin{array}{c}\text { Condenser } \\
\text { Tube } \\
\text { Diameter } \\
\left(\mathrm{cm}^{\wedge} 3\right)\end{array}$ & $\begin{array}{c}\text { Evaporator } \\
\text { Thermal } \\
\text { Load } \\
(\text { Watts })\end{array}$ & $\begin{array}{c}\text { Compressor } \\
\text { Power }\end{array}$ & $\begin{array}{c}\text { Average } \\
\text { COP }\end{array}$ & $\begin{array}{c}\text { Normalized } \\
\text { COP }\end{array}$ \\
\hline 1 & 0.1778 & 1.1430 & 200.00 & 0.5606 & 3948.00 & 3407.46 & 1.1586 & 0.7218 \\
& & & & & & & & \\
41 & 0.2568 & 1.6519 & 122.41 & 0.6736 & 3591.61 & 2265.14 & 1.5856 & 0.9878 \\
42 & 0.2568 & 1.6849 & 120.01 & 0.6736 & 3576.02 & 2228.32 & 1.6048 & 0.9998 \\
43 & 0.2568 & 1.6519 & 120.01 & 0.6871 & 3577.72 & 2232.11 & 1.6028 & 0.9986 \\
45 & 0.2566 & 1.6531 & 120.01 & 0.6733 & 3575.71 & 2228.42 & 1.6046 & 0.9996 \\
46 & 0.2564 & 1.6543 & 120.01 & 0.6729 & 3578.77 & 2234.00 & 1.6020 & 0.9980 \\
& & & & & & & & \\
58 & 0.2564 & 1.6523 & 120.01 & 0.6735 & 3573.05 & 2234.44 & 1.5991 & 0.9962 \\
59 & 0.2565 & 1.6524 & 120.01 & 0.6735 & 3568.87 & 2223.37 & 1.6052 & 1.0000 \\
60 & 0.2565 & 1.6524 & 120.01 & 0.6735 & 3576.70 & 2232.51 & 1.6021 & 0.9981 \\
\hline
\end{tabular}

Initial System Pressure $=1.627 \mathrm{MPa}(236 \mathrm{psi})$

\begin{tabular}{|c|c|c|c|c|c|c|c|c|}
\hline $\begin{array}{c}\text { Solution } \\
\text { Loop } \\
\text { Count }\end{array}$ & $\begin{array}{l}\text { Expansion } \\
\text { Device } \\
\text { Diameter } \\
(\mathrm{cm}) \\
\end{array}$ & $\begin{array}{l}\text { Transfer } \\
\text { Line } \\
\text { Diameter } \\
(\mathrm{cm}) \\
\end{array}$ & $\begin{array}{c}\text { Compressor } \\
\text { Displacement } \\
\left(\mathrm{cm}^{\wedge} 3\right)\end{array}$ & $\begin{array}{l}\text { Condenser } \\
\text { Tube } \\
\text { Diameter } \\
(\mathrm{cm}) \\
\end{array}$ & $\begin{array}{c}\text { Evaporator } \\
\text { Thermal } \\
\text { Load } \\
\text { (Watts) } \\
\end{array}$ & $\begin{array}{c}\text { Compressor } \\
\text { Power } \\
\text { (Watts) } \\
\end{array}$ & $\begin{array}{c}\text { Average } \\
\text { COP }\end{array}$ & $\begin{array}{l}\text { Normalized } \\
\text { COP }\end{array}$ \\
\hline 1 & 0.1778 & 1.1430 & 200.00 & 0.5606 & 4468.29 & 3915.14 & 1.1413 & 0.7111 \\
\hline 23 & 0.2234 & 1.4551 & 120.01 & 0.6848 & 3949.27 & 2466.73 & 1.6010 & 0.9975 \\
\hline 24 & 0.2201 & 1.4942 & 120.01 & 0.6740 & 3938.71 & 2455.38 & 1.6041 & 0.9994 \\
\hline 25 & 0.2201 & 1.4942 & 120.01 & 0.6740 & 3945.49 & 2458.91 & 1.6046 & 0.9997 \\
\hline 35 & 0.2201 & 1.5239 & 120.01 & 0.6739 & 3943.63 & 2460.74 & 1.6026 & 0.9985 \\
\hline 36 & 0.2201 & 1.4940 & 120.01 & 0.6873 & 3944.82 & 2457.81 & 1.6050 & 1.0000 \\
\hline 37 & 0.2201 & 1.4940 & 120.01 & 0.6740 & 3945.59 & 2461.90 & 1.6027 & 0.9985 \\
\hline
\end{tabular}

Initial System Pressure $=1.689 \mathrm{MPa}(245 \mathrm{psi})$

\begin{tabular}{|c|c|c|c|c|c|c|c|c|}
\hline $\begin{array}{l}\text { Solution } \\
\text { Loop } \\
\text { Count }\end{array}$ & $\begin{array}{l}\text { Expansion } \\
\text { Device } \\
\text { Diameter } \\
(\mathrm{cm}) \\
\end{array}$ & $\begin{array}{l}\text { Transfer } \\
\text { Line } \\
\text { Diameter } \\
(\mathrm{cm})\end{array}$ & $\begin{array}{c}\text { Compressor } \\
\text { Displacement } \\
\left(\mathrm{cm}^{\wedge} 3\right)\end{array}$ & $\begin{array}{l}\text { Condenser } \\
\text { Tube } \\
\text { Diameter } \\
(\mathrm{cm})\end{array}$ & $\begin{array}{l}\text { Evaporator } \\
\text { Thermal } \\
\text { Load (Ave.) } \\
\text { (Watts) }\end{array}$ & $\begin{array}{c}\text { Average } \\
\text { Compressor } \\
\text { Power } \\
\text { (Watts) }\end{array}$ & $\begin{array}{c}\text { Average } \\
\text { COP }\end{array}$ & $\begin{array}{l}\text { Normalized } \\
\text { COP }\end{array}$ \\
\hline 1 & 0.1778 & 1.1430 & 200.00 & 0.5606 & 4672.35 & 4154.08 & 1.1248 & 0.6982 \\
\hline 31 & 0.1966 & 1.5680 & 120.01 & 0.6663 & 4065.68 & 2528.38 & 1.6080 & 0.9982 \\
\hline 32 & 0.1966 & 1.5680 & 120.01 & 0.6662 & 4067.67 & 2525.13 & 1.6109 & 1.0000 \\
\hline 33 & 0.2005 & 1.5680 & 120.01 & 0.6662 & 4069.10 & 2539.52 & 1.6023 & 0.9947 \\
\hline 111 & 0.2153 & 1.6047 & 120.01 & 0.6897 & 4065.35 & 2532.57 & 1.6052 & 0.9965 \\
\hline 112 & 0.2584 & 1.6079 & 120.01 & 0.6469 & 4064.21 & 2524.64 & 1.6098 & 0.9993 \\
\hline 113 & 0.2412 & 1.6066 & 120.01 & 0.6586 & 4066.77 & 2535.30 & 1.6041 & 0.9958 \\
\hline 146 & 0.2228 & 1.6250 & 120.01 & 0.6511 & 4063.70 & 2527.80 & 1.6076 & 0.9980 \\
\hline 147 & 0.2228 & 1.6185 & 120.01 & 0.6506 & 4063.32 & 2524.04 & 1.6099 & 0.9994 \\
\hline 148 & 0.2227 & 1.6141 & 120.01 & 0.6503 & 4065.97 & 2532.34 & 1.6056 & 0.9967 \\
\hline
\end{tabular}

Initial System Pressure $=1.758 \mathrm{MPa}(255 \mathrm{psi})$ 


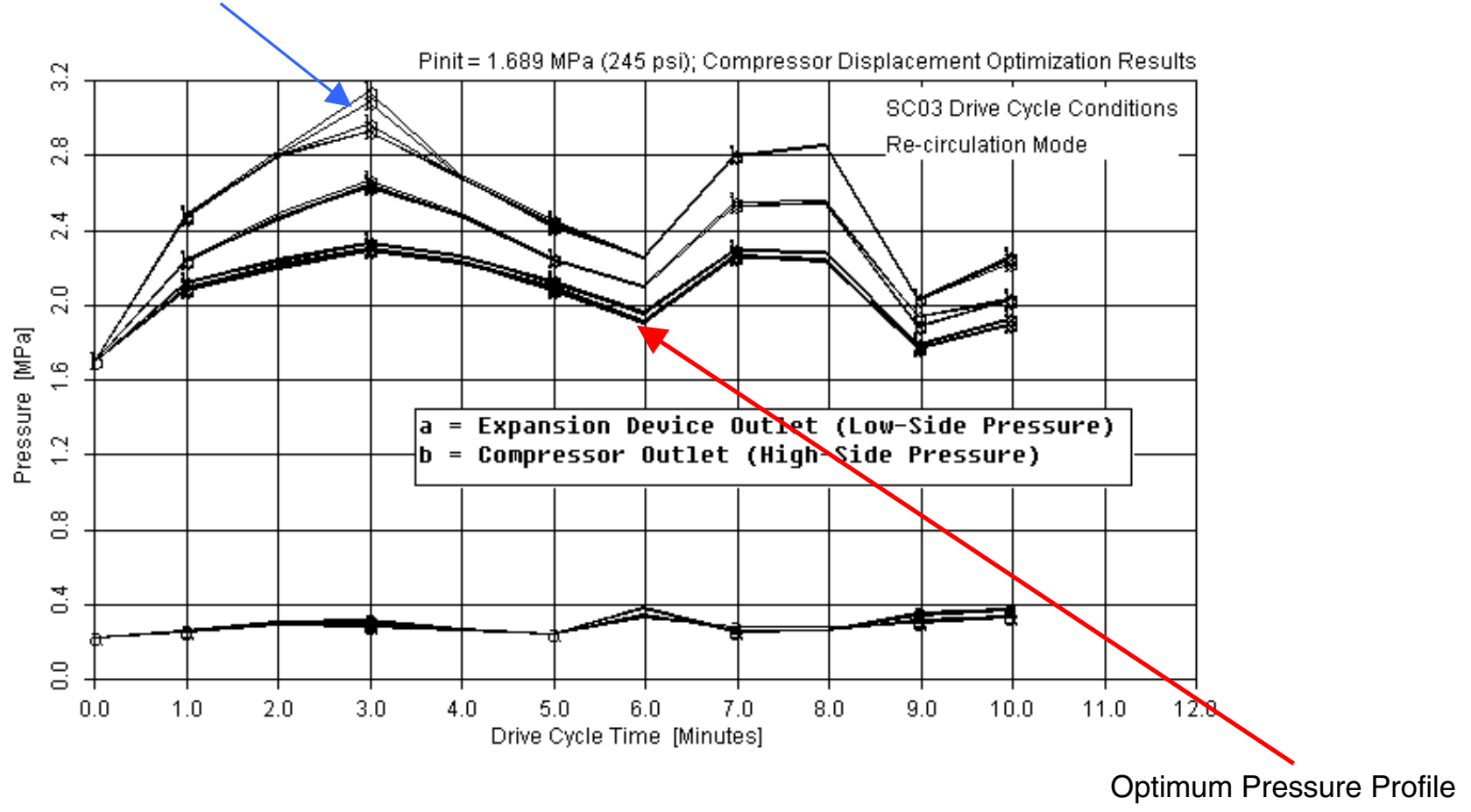

Figure 24 - Optimum Pressure Profile Maximizing COP during SC03 Drive Cycle

Additional studies of flow quality conditions in the condenser during these system optimizations also revealed that optimum flow quality profiles also exist associated with maximum COP conditions. Figure 25 demonstrates an example of the optimum flow quality profiles at certain positions in the condenser's two-phase region. The legend numbering again corresponds to the condenser lump numbering shown in Figure 5 . The darker flow quality lines again show the distinct clustering about the optimum flow quality profiles once SINDA/FLUINT has determined and begins focusing on the optimum system design. These optimum flow quality profiles are certainly associated with optimum two-phase heat transfer conditions within the condenser, although the work to date has not yet begun to quantify this relationship. Future work in this area will address this effect.

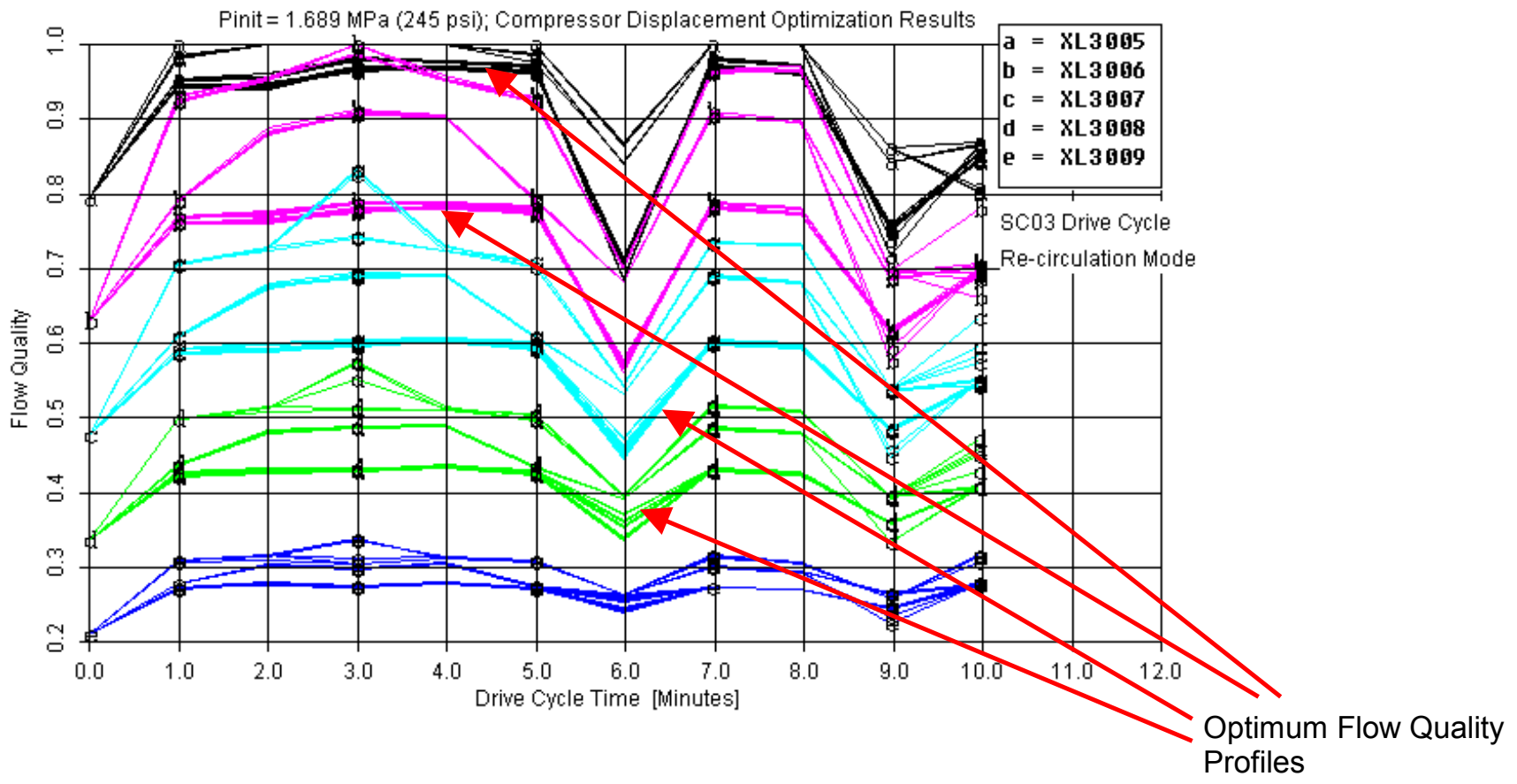

Figure 25 - Optimum Flow Quality Profiles Maximizing COP during SC03 Drive Cycle 
US06 DRIVE CYCLE RESULTS - Multiple variable optimization studies were also extended to simultaneous optimizations of three design parameters, expansion device diameter, transfer line diameter, and condenser tube diameter, over the US06 drive cycle. All system assumptions used in the SC03 optimization studies were maintained. As before system optimization runs started from multiple initial conditions with the constant initial pressure of $1.689 \mathrm{MPa}(245 \mathrm{psi})$. Table 3 displays the results of the five separate US06-drive-cycle optimization runs using the different initial starting conditions.

Table 3 shows that this US06 design optimization produced a much different optimum system solution than that for the SC03 drive cycle. The optimum system performance for US06 drive cycle conditions was discovered at an expansion device diameter of $0.147 \mathrm{~cm}$ or $0.058 \mathrm{inch}$, a transfer line diameter of $2.07 \mathrm{~cm}$ or 0.813 inch, and a condenser tube diameter of $0.597 \mathrm{~cm}$ or 0.235 inch. This demonstrates that optimum system designs can vary depending on the drive cycle because of the different compressor and system flow dynamics. Therefore, a sophisticated optimization strategy simultaneously incorporating the impact of various drive cycles is required in future system design optimizations. The fact that the optimum $\mathrm{A} / \mathrm{C}$ system design can vary with drive cycle conditions also creates the potential opportunity for a dynamically variable $\mathrm{A} / \mathrm{C}$ system design based on drive cycle conditions. Some design work is being done in this area, but this work can greatly benefit from the dynamic $A / C$ modeling capability presented here.

Finally, the quadruple-variable optimization studies, investigating combined simultaneous optimization of compressor displacement, expansions device diameter, transfer line diameter, and condenser tube diameter, were extended to the US06 drive cycle. Table 4 shows the results of this A/C system optimization for an initial system pressure of $1.703 \mathrm{MPa}(247 \mathrm{psi})$. This optimization was run for the same set of conditions as the SC03 optimization results in Table 2. The optimum A/C system design for the US06 drive cycle (highlighted in red) was again somewhat different from optimum designs for the SC03 drive cycle in Table 2. This highlights (1) the need for optimizing the system design over a number of different drive cycles and (2) the opportunity for dynamically variable $A / C$ systems to optimize performance dependent on drive cycle conditions. However, again a quite significant increase in A/C system COP during a US06 drive cycle, from about 0.99 to 1.24 , is possible for the optimum combination of compressor displacement, expansion device diameter, transfer line diameter, and condenser tube diameter. The reason for this is quite the same as in the SC03 drive cycle case in Table 2. An optimum pressure profile, flow quality profile, and heat transfer conditions exist that maximize the A/C system performance. In this US06 optimization study, compressor power decreased by $29.4 \%$ compared to the initial offoptimum system design. This compressor power decrease would again correspond to a 1.8-3.5 miles per gallon fuel economy increase in today's vehicles. Figure 26 shows the optimum high-side system pressure profile, $\left[p_{H}(t)\right]_{o p t}$, discovered and associated with the optimum system performance point. Figure 27 displays the optimum flow quality profiles in the condenser two-phase region associated with the optimum system performance point.

A final note is required on this system optimization work. The optimization results shown in Tables 1 and 3 do not show large improvements in COP because of the particular choices of design variables selected to optimize, the convergence criteria that limited the global search in favor of maintaining computational stability, and the results to-date only represent a work-in-progress. However, Tables 2 and 4 show very significant improvements in $\mathrm{A} / \mathrm{C}$ system COP if the proper combination of system design variables are optimized. The intent of this work was to present this new transient $\mathrm{A} / \mathrm{C}$ system analysis and optimization tool, and show some high-level system design conclusions reached to date. Future work will simultaneously optimize more system variables with more sophisticated objective functions, involving system weight, cost, cabin cool-down time, and others, in identifying optimum vehicle $A / C$ system designs. 
Table 3 - Optimum Expansion Device Diameter, Transfer Line Diameter, and Condenser Line Diameter Maximizing

COP during the US06 Drive Cycle (Optimum in Red)

\begin{tabular}{|c|c|c|c|c|c|}
\hline $\begin{array}{c}\text { Run } \\
\# 1 \\
\text { Loop } \\
\#\end{array}$ & $\begin{array}{l}\text { Expansion } \\
\text { Device } \\
\text { Diameter } \\
\text { (Inch) }\end{array}$ & $\begin{array}{l}\text { Transfer } \\
\text { Line } \\
\text { Diameter } \\
\text { (Inch) }\end{array}$ & $\begin{array}{l}\text { Condenser } \\
\text { Line } \\
\text { Diameter } \\
\text { (Inch) }\end{array}$ & $\begin{array}{l}\text { Average } \\
\text { COP }\end{array}$ & $\begin{array}{l}\text { Normalized } \\
\text { COP }\end{array}$ \\
\hline 1 & .1676 & 1.27 & .5405 & .984 & .982 \\
\hline 86 & 2775 & 2.0699 & .4737 & 1.002 & 1 \\
\hline $\begin{array}{c}\text { Run } \\
\# 2 \\
\text { Loop } \\
\#\end{array}$ & $\begin{array}{l}\text { Expansion } \\
\text { Device } \\
\text { Diameter } \\
(\mathrm{cm})\end{array}$ & $\begin{array}{l}\text { Transfer } \\
\text { Line } \\
\text { Diameter } \\
\text { (cm) }\end{array}$ & $\begin{array}{l}\text { Condenser } \\
\text { Line } \\
\text { Diameter } \\
(\mathrm{cm})\end{array}$ & $\begin{array}{c}\text { Average } \\
\text { COP }\end{array}$ & $\begin{array}{l}\text { Normalized } \\
\text { COP }\end{array}$ \\
\hline 1 & 0.1727 & 1.27 & 0.5456 & 0.993 & 0.9971 \\
\hline 18 & 0.1834 & 1.3715 & 0.5793 & 0.996 & 1 \\
\hline $\begin{array}{c}\text { Run } \\
\# 3 \\
\text { Loop } \\
\# \\
\end{array}$ & $\begin{array}{l}\text { Expansion } \\
\text { Device } \\
\text { Diameter } \\
(\mathrm{cm})\end{array}$ & $\begin{array}{l}\text { Transfer } \\
\text { Line } \\
\text { Diameter } \\
(\mathrm{cm})\end{array}$ & $\begin{array}{c}\text { Condenser } \\
\text { Line } \\
\text { Diameter } \\
(\mathrm{cm}) \\
\end{array}$ & $\begin{array}{c}\text { Average } \\
\text { COP }\end{array}$ & $\begin{array}{c}\text { Normalized } \\
\text { COP }\end{array}$ \\
\hline 1 & .1778 & 1.143 & 0.5606 & 0.982 & 0.9697 \\
\hline 99 & 0.1473 & 2.0646 & 0.5968 & 1.013 & 1 \\
\hline $\begin{array}{c}\text { Run } \\
\# 4 \\
\text { Loop } \\
\#\end{array}$ & $\begin{array}{l}\text { Expansion } \\
\text { Device } \\
\text { Diameter } \\
(\mathrm{cm})\end{array}$ & $\begin{array}{l}\text { Transfer } \\
\text { Line } \\
\text { Diameter } \\
\text { (cm) }\end{array}$ & $\begin{array}{l}\text { Condenser } \\
\text { Line } \\
\text { Diameter } \\
(\mathrm{cm})\end{array}$ & $\begin{array}{c}\text { Average } \\
\text { COP }\end{array}$ & $\begin{array}{c}\text { Normalized } \\
\text { COP }\end{array}$ \\
\hline 1 & 0.1778 & 1.143 & 0.5606 & 0.982 & 0.9741 \\
\hline 74 & 0.2386 & 1.6740 & 0.6395 & 1.008 & 1 \\
\hline 81 & 0.2050 & 1.5796 & 0.6134 & 1.007 & 0.9996 \\
\hline $\begin{array}{c}\text { Run } \\
\# 5 \\
\text { Loop } \\
\#\end{array}$ & $\begin{array}{l}\text { Expansion } \\
\text { Device } \\
\text { Diameter } \\
(\mathrm{cm})\end{array}$ & $\begin{array}{l}\text { Transfer } \\
\text { Line } \\
\text { Diameter } \\
\text { (cm) }\end{array}$ & $\begin{array}{l}\text { Condenser } \\
\text { Line } \\
\text { Diameter } \\
(\mathrm{cm})\end{array}$ & $\begin{array}{c}\text { Average } \\
\text { COP }\end{array}$ & $\begin{array}{l}\text { Normalized } \\
\text { COP }\end{array}$ \\
\hline 1 & 0.1778 & 1.2192 & 0.5570 & 0.988 & 0.9798 \\
\hline 100 & 0.2565 & 1.6877 & 0.6092 & 1.008 & 1 \\
\hline
\end{tabular}


Table 4 - Quadruple-Variable Optimization Results for US06 Drive Cycle Conditions (Simultaneous Optimization of Compressor Displacement, Expansion Device Diameter, Transfer Line Diameter, Condenser Tube Diameter)

\begin{tabular}{|c|c|c|c|c|c|c|c|c|}
\hline $\begin{array}{c}\text { Solution } \\
\text { Loop } \\
\text { Count }\end{array}$ & $\begin{array}{l}\text { Expansion } \\
\text { Device } \\
\text { Diameter } \\
\text { (cm) }\end{array}$ & $\begin{array}{l}\text { Transfer } \\
\text { Line } \\
\text { Diameter } \\
\text { (cm) }\end{array}$ & $\begin{array}{c}\text { Compressor } \\
\text { Displacement } \\
\left(\mathrm{cm}^{\wedge} 3\right)\end{array}$ & $\begin{array}{l}\text { Condenser } \\
\text { Tube } \\
\text { Diameter } \\
(\mathrm{cm})\end{array}$ & $\begin{array}{l}\text { Evaporator } \\
\text { Thermal } \\
\text { Load (Ave.) } \\
\text { (Watts) }\end{array}$ & $\begin{array}{c}\text { Average } \\
\text { Compressor } \\
\text { Power } \\
\text { (Watts) }\end{array}$ & $\begin{array}{l}\text { Average } \\
\text { COP }\end{array}$ & $\begin{array}{l}\text { Normalized } \\
\text { COP }\end{array}$ \\
\hline 1 & 0.1778 & 1.2192 & 200.00 & 0.5570 & 4824.93 & 4898.35 & 0.9850 & 0.7923 \\
\hline 2 & 0.1814 & 1.2192 & 200.00 & 0.5570 & 4818.51 & 4887.42 & 0.9859 & 0.7930 \\
\hline 3 & 0.1778 & 1.2192 & 203.99 & 0.5570 & 4844.58 & 4967.00 & 0.9754 & 0.7845 \\
\hline 4 & 0.1778 & 1.2436 & 200.00 & 0.5570 & 4723.58 & 4726.70 & 0.9993 & 0.8038 \\
\hline 5 & 0.1778 & 1.2192 & 200.00 & 0.5681 & 4803.16 & 4862.54 & 0.9878 & 0.7945 \\
\hline 6 & 0.1858 & 1.4630 & 159.99 & 0.6356 & 4555.15 & 4103.96 & 1.1099 & 0.8927 \\
\hline 7 & 0.1855 & 1.4528 & 161.69 & 0.6323 & 4563.13 & 4131.49 & 1.1045 & 0.8883 \\
\hline 8 & 0.1892 & 1.4528 & 161.69 & 0.6323 & 4561.51 & 4128.29 & 1.1049 & 0.8887 \\
\hline 13 & 0.1914 & 1.5278 & 129.35 & 0.6515 & 4325.71 & 3537.97 & 1.2227 & 0.9834 \\
\hline 14 & 0.1952 & 1.5278 & 129.35 & 0.6515 & 4325.81 & 3533.49 & 1.2242 & 0.9847 \\
\hline 15 & 0.1914 & 1.5278 & 131.93 & 0.6515 & 4335.45 & 3570.86 & 1.2141 & 0.9765 \\
\hline 34 & 0.2078 & 1.5733 & 127.51 & 0.6663 & 4309.11 & 3498.64 & 1.2317 & 0.9906 \\
\hline 35 & 0.2078 & 1.6048 & 124.99 & 0.6663 & 4295.7 & 3455.82 & 1.2430 & 0.9998 \\
\hline 36 & 0.2078 & 1.5733 & 124.99 & 0.6797 & 4298.33 & 3464.07 & 1.2408 & 0.9980 \\
\hline 42 & 0.2078 & 1.6072 & 124.99 & 0.6652 & 4295.44 & 3457.70 & 1.2423 & 0.9992 \\
\hline 43 & 0.2078 & 1.5757 & 124.99 & 0.6785 & 4293.97 & 3454.48 & 1.2430 & 0.9998 \\
\hline 44 & 0.2080 & 1.5763 & 124.99 & 0.6656 & 4297.88 & 3456.83 & 1.2433 & 1.0000 \\
\hline 45 & 0.2080 & 1.5763 & 124.99 & 0.6656 & 4301.36 & 3466.29 & 1.2409 & 0.9981 \\
\hline 46 & 0.2121 & 1.5763 & 124.99 & 0.6656 & 4300.74 & 3463.09 & 1.2419 & 0.9989 \\
\hline 57 & 0.2080 & 1.5769 & 124.99 & 0.6658 & 4297.12 & 3464.44 & 1.2404 & 0.9976 \\
\hline 58 & 0.2080 & 1.5769 & 124.99 & 0.6658 & 4293.6 & 3459.09 & 1.2413 & 0.9984 \\
\hline 59 & 0.2080 & 1.5769 & 124.99 & 0.6658 & 4299.92 & 3463.30 & 1.2416 & 0.9986 \\
\hline
\end{tabular}




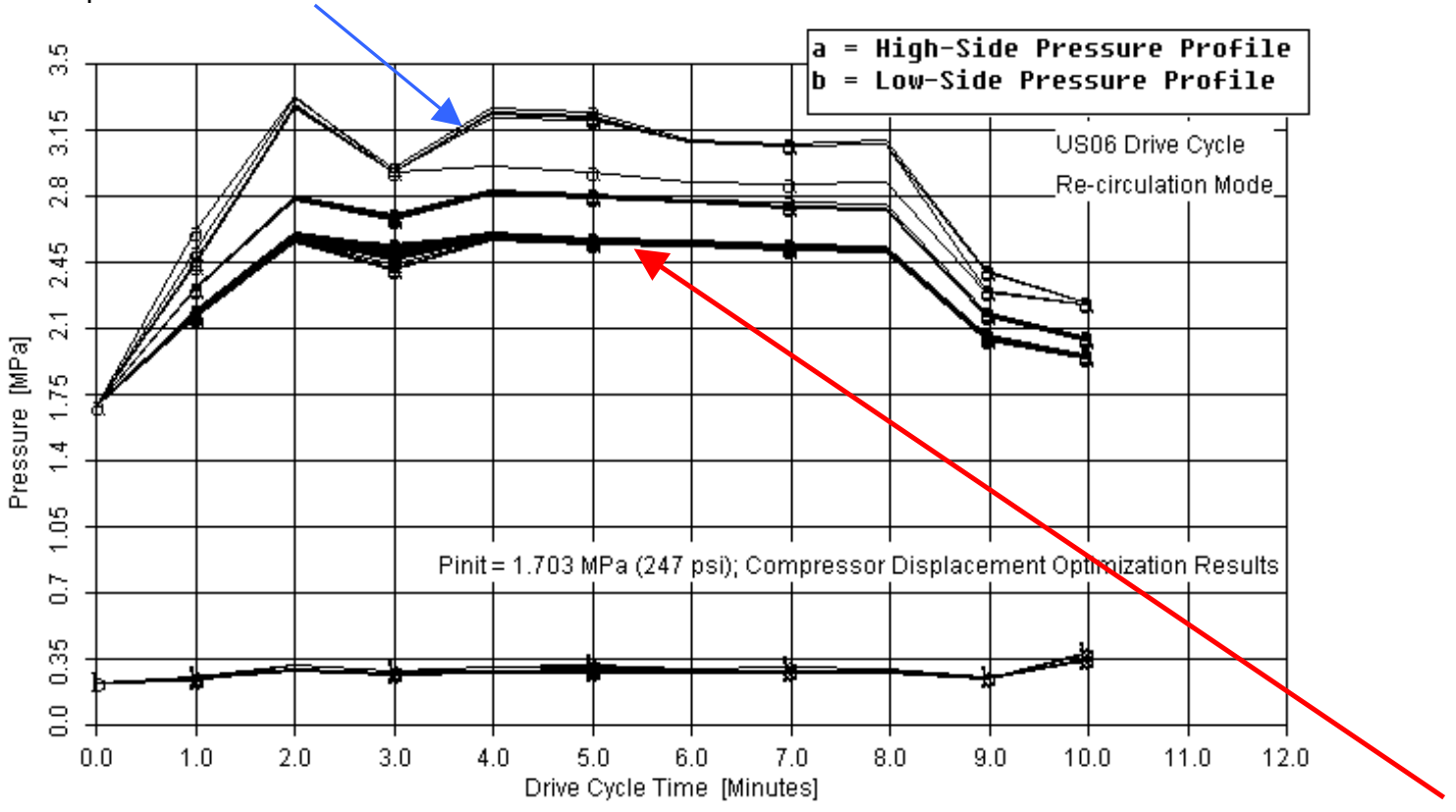

Optimum Pressure Profile

Figure 26 - Optimum Pressure Profile Maximizing COP during US06 Drive Cycle

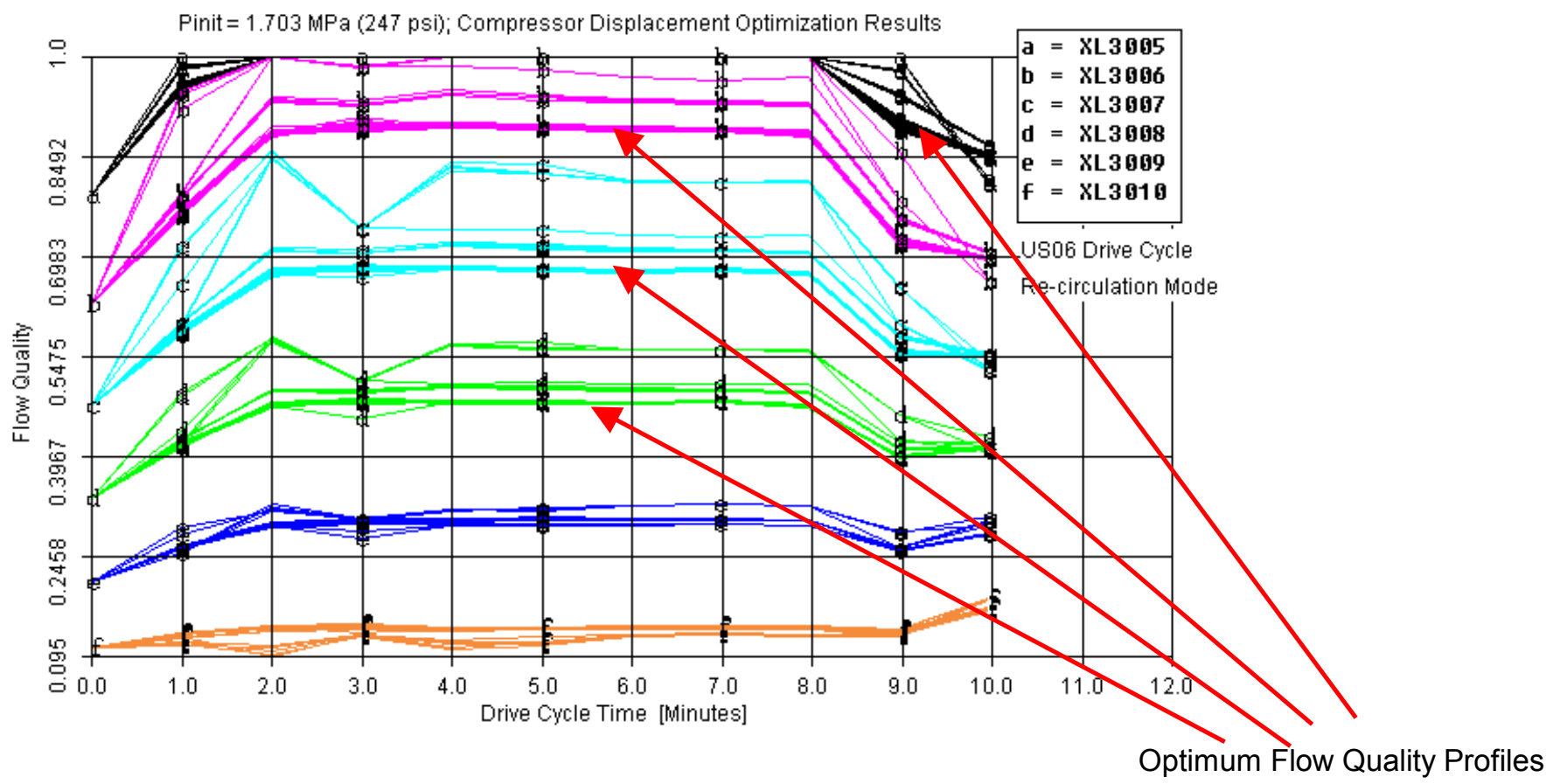

Figure 27 - Optimum Flow Quality Profiles Maximizing COP during US06 Drive Cycle

\subsection{ADVISOR INTEGRATION}

NREL has integrated the transient A/C system model into its ADVISOR vehicle system analysis software. Integration of the transient A/C system model into ADVISOR represents a subset of NREL's Digital Functional Vehicle (DFV) project that intends to virtually simulate many of the first-order, energy-management and emissionsproducing mechanisms in the vehicle design process. DFV creates a virtual vehicle design environment that can shorten vehicle design cycle times, reduce the number of required test prototypes, and produce more optimized 
vehicle designs. The SINDA/FLUINT analysis software and the ADVISOR vehicle system analysis software contain built-in optimization capabilities that will optimize the vehicle $\mathrm{A} / \mathrm{C}$ system within the overall vehicle design optimization process. This allows NREL to simultaneously optimize the A/C system with other vehicle systems, such as passenger cabin systems, engine coolant systems, energy recovery systems, and other dynamic systems using system co-simulation.

NREL's newly developed vehicle solar thermal load simulator (VSOLE) program that predicts transient vehicle solar thermal loads for a variety of vehicle configurations has also been integrated with the transient $A / C$ system model and ADVISOR. The solar load simulator predicts the transient solar thermal loads in the vehicle cabin for any vehicle drive direction, varying geographic locations, and a number of vehicle glass packages. It calculates the predicted solar thermal load as a function of time into a file which the transient A/C system model automatically reads real-time during an analysis run. NREL can now incorporate vehicle dynamic solar loads into any transient A/C system simulation or optimization. Figure 28 displays the input and output graphical user interface (GUI) for VSOLE. This gives an idea of the various solar thermal loads that are calculated, such as transmitted, absorbed, and reflected energies. Figure 28 also shows the detail to which vehicle glazing can be specified (i.e., window angle, glazing area, glazing type, etc.) and the vehicle environmental parameters (i.e., solar radiation source, vehicle drive direction, time of day, etc.) required as input.

ADVISOR serves as the master in controlling both VSOLE and the transient $A / C$ system model. The transient $\mathrm{A} / \mathrm{C}$ model is controlled via a SIMULINK S-Function that serves as the communication link between SINDA/FLUINT and Matlab. The S-Function is accessed by ADVISOR at each point in the vehicle performance time integration, allowing ADVISOR to communicate updated vehicle performance data to SINDA/FLUINT and SINDA/FLUINT to pass back updated compressor power, cabin temperature and other A/C system parameters to ADVISOR. The VSOLE model is implemented within ADVISOR as a GUI option at the start of ADVISOR. VSOLE calculations for a specific vehicle are then performed once and the results for vehicle dynamic solar loads (i.e., absorbed, reflected, and transmitted solar thermal loads versus time) are stored in a file that SINDA/FLUINT subsequently accesses during the transient $A / C$ analysis. Future work will ultimately include $A / C$ system design parameter selection and run control parameter selection within the ADVISOR GUI.

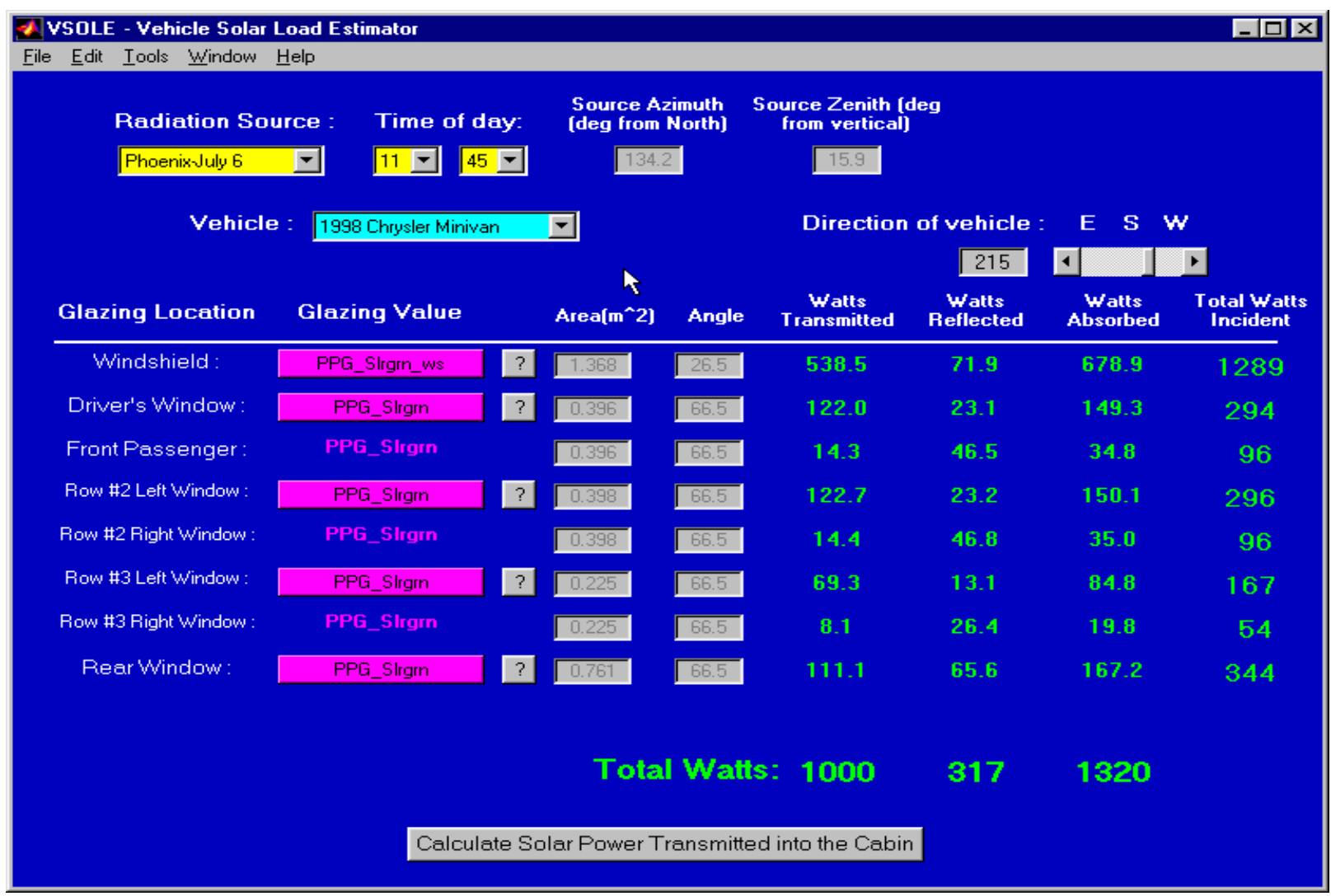

Figure 28 - VSOLE Input and Output Graphical User Interface 


\subsection{FUTURE WORK}

The transient $\mathrm{A} / \mathrm{C}$ system performance analysis tool has been developed and demonstrated, and various optimization capabilities and studies have been demonstrated to date. Future work in FY 2001 and possibly FY 2002 will involve additional investigations in transient A/C system performance to (1) better understand optimum design conditions as functions of operating pressure and temperature; (2) better understand optimum two-phase heat transfer conditions and their relation to optimum flow quality profiles within the condenser; and (3) simultaneously optimize more system variables with more sophisticated objective functions, involving system weight, cost, cabin cool-down time, and others, in identifying optimum vehicle $\mathrm{A} / \mathrm{C}$ system designs. Future work will also focus on investigating the effects of variable displacement compressors, variable orifice valves (VOVs) and electrical-driven compressors in optimizing transient $A / C$ system performance to increase vehicle fuel economy and reduce vehicle emissions. NREL's desire also is to begin looking at specific A/C system designs of importance on specific vehicle platform projects at DaimlerChrysler, General Motors, Ford Motor Company, Visteon Corporation, and Delphi Automotive Systems to perform A/C system design optimization within overall vehicle design optimizations using ADVISOR. NREL has requested specific A/C system design data to develop project-specific A/C system models, perform A/C system optimizations relevant to industry-specific vehicle projects, and validate the transient $\mathrm{A} / \mathrm{C}$ model against "real-world" experimental data in collaboration with automotive industry partners. NREL will also expand the model's use to heavy vehicle applications.

\subsection{CONCLUSIONS}

NREL has developed a robust, flexible, and fully transient vehicle Air-Conditioning model, integrated with a simplified cabin thermal environment model, in the SINDA/FLUINT analysis software environment. It is a 1dimensional, thermal/hydraulic simulation tool that simultaneously models the entire $A / C$ system and its components for various external vehicle environments and drive cycle conditions. The transient thermal/hydraulic model takes a fundamental-principle approach to capture all the relevant physics of transient $\mathrm{A} / \mathrm{C}$ system performance, including two-phase flow effects in the evaporator and condenser, refrigerant and component inertia effects, compressor speed effects, air side heat transfer on the condenser/evaporator, vehicle speed effects, timeand position-varying heat transfer conditions in the evaporator and condenser, vehicle speed effects, temperaturedependent properties, environmental loading and ambient temperature conditions on the vehicle, and integration with a simplified cabin thermal model. It has demonstrated capability to predict transient system pressures and temperatures, mass flow rates, flow quality and flow regime conditions, transient compressor power, transient evaporator and condenser heat loads, and transient cabin thermal conditions during any user-specified vehicle drive cycle conditions. The fundamental-principles approach of the integrated system is the only way to truly optimize the A/C system to maximize performance (i.e., minimize power consumption). Using the model, NREL has demonstrated system-level design interdependencies among components, and performed multi-parameter, system-level optimization of vehicle air-conditioning systems to improve vehicle fuel economy and reduce emissions. The model currently focuses on R-134a A/C systems, but future work is planned to investigate advanced alternative refrigerant systems such as carbon dioxide systems.

The model was developed within SINDA/FLUINT analysis software and has been integrated with NREL's ADVISOR vehicle simulation code and NREL's vehicle solar thermal load estimator code to perform co-simulations of vehicle systems, air-conditioning systems, and cabin thermal/fluid performance for user-specified environmental and vehicle driving conditions. NREL's vehicle solar thermal load simulator predicts transient solar thermal loads on a vehicle for various drive directions, geographic locations, vehicle glass packages, and vehicle configurations. The SINDA/FLUINT transient A/C model then uses the solar simulator transient loads in predicting cabin thermal conditions. Model development continues to increase its analytic power and flexibility, while the SINDA/FLUINT model is continuously integrated within NREL's ADVISOR vehicle system analysis software. This analytic tool integration will allow NREL to optimize A/C system performance within the overall vehicle design optimization process using ADVISOR.

Various robust and powerful $\mathrm{A} / \mathrm{C}$ system optimization capabilities and studies are demonstrated and reported herein. The transient $A C /$ cabin model has been used to perform multiple-variable optimization of $A / C$ system performance during SCO3 and US06 drive cycles. Because of the strong inter-dependencies among A/C system and cabin design variable impacts, the results have demonstrated that multiple variable optimization is critical to truly optimizing A/C system performance for various drive cycles. Since various drive cycles can produce different optimum system designs, sophisticated optimization strategies must be developed simultaneously incorporating the effects of different drive cycles in the system optimization process. System optimization studies have shown 
significant improvements in $\mathrm{A} / \mathrm{C}$ system performance are possible through integrated system design and optimization. Recent system analyses indicate 1.8-3.5 mpg improvement is possible through integrated $A / C$ system optimization of interrelated component effects. Optimum, drive-cycle-dependent pressure profiles, flow quality profiles, and heat transfer conditions do exist that maximize A/C system performance. This analysis tool is able to identify and quantify such optimum conditions. This has shown that dynamic intelligently controlled A/C systems, based on continuous feedback of environmental and vehicle driving conditions (i.e., vehicle speed, compressor speed, ambient temperatures, humidity, and solar load conditions) and the ability to quantify systemlevel impacts, offer tremendous opportunities to operate vehicle $A / C$ systems at optimum maximum performance under a variety of drive cycle conditions. This will allow NREL, DOE, and the automotive industry to increase vehicle fuel economy and reduce emissions across a wide range of light-duty vehicles, sport-utility vehicles, and heavy-duty vehicles.

Future work will focus on (1) additional A/C system optimization investigations, including variable displacement compressor, VOV, and electric-driven compressor systems, and (2) validating the transient A/C system model with "real world" experimental data on industry-relevant systems and collaborative projects with industry partners, such as DaimlerChrysler, General Motors, Visteon Corporation, and Delphi Automotive Systems.

\section{ACKNOWLEDGMENTS}

The author would like to thank Mr. Roland Gravel and Mr. Robert Kost at DOE for their support of this work through the HEV Propulsion Systems Program under DOE contract \#DE-AC36-99G010337. The author gratefully thanks Mr. Al Kargilis of DaimlerChrysler Corporation, Jeep \& Truck Engineering for his helpful advice identifying nominal system parameters. The author also gratefully thanks Dr. Mingyu Wang of Delphi Automotive Systems Harrison Thermal Systems for his insightful discussions, and Dr. Greg Barber of NREL for the vehicle solar thermal load simulator program development and implementation within ADVISOR. 


\section{REFERENCES}

1. Bevilacqua, O.M., "Effect of Air Conditioning on Regulated Emissions for In-Use Vehicles," Clean Air Vehicle Technology Center, Oakland, CA, Phase I Final Report Prepared for Coordinating Research Council, Inc., Atlanta, GA, CRC Project E-37, October 1999.

2. Nadamoto, H. and Kubota, A., "Power Saving with the Use of Variable Displacement Compressors," in Proceedings of SAE International Congress and Exposition, SAE Technical Paper \#1999-01-0875, Detroit, MI, March 1999.

3. Wang, M., Farley, and D.L., Leitzel, L.L., "Air Conditioning System Head Pressure Spike during Vehicle Acceleration," in Proceedings of SAE 2000 World Congress, SAE Technical Paper \#2000-01-0973, Detroit, MI, March 2000.

4. Khamsi, Y. and Petitjean, C., "Validation of Automotive Passenger Compartment and Its Air Conditioning System Modeling," in Proceedings of SAE 2000 World Congress, SAE Technical Paper \#2000-01-0982, Detroit, MI, March 2000.

5. Hyun, L.K. and Wong, J.-F., "Thermal Design Study of a High Performance Evaporator for the Automotive Air Conditioner," in Proceedings of SAE International Congress and Exposition, SAE Technical Paper \#1999-011191, Detroit, MI, March 1999.

6. Kelemen, K., Tarunraj, S., and Mayne, R., "Modeling of an Automotive Air-Conditioning System," in Proceedings of SAE 2000 World Congress, SAE Technical Paper \#2000-01-1269, Detroit, MI, March 2000.

7. Cullimore \& Ring Technologies, Inc., "SINDA/FLUINT General Purpose Thermal/Fluid Network Analyzer," in User's Manual, Version 4.3, June 2000.

8. Brooker, A., Hendricks, T., Johnson, V., Kelly, K., Markel, T., O’Keefe, M., Sprik, S., and Wipke, K., "ADVISOR 3.1 Documentation," National Renewable Energy Laboratory Advanced Vehicle Simulator, February 2001, http://www.ctts.nrel.gov/analysis/advisor_doc/.

9. Kargilis, A., Design \& Development of Automotive Air Conditioning Systems, Course Textbook, University Consortium for Continuing Education, Encino, CA, www.ucce.edu., February 2000. 
Supplemental Federal Test Procedure Drive Cycles
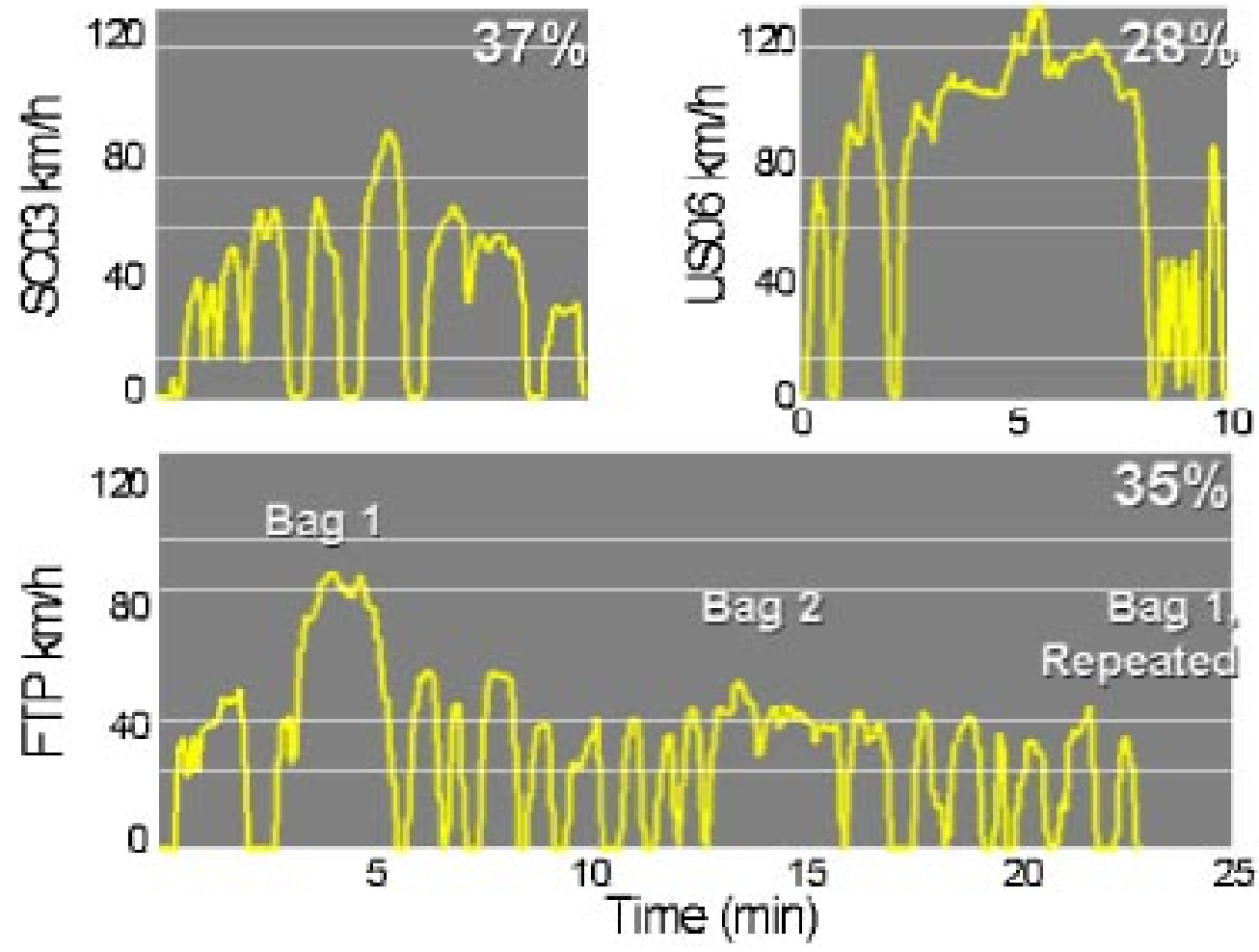


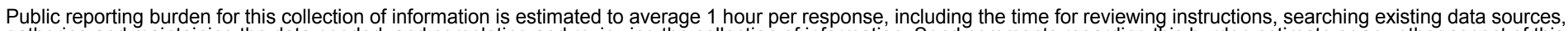

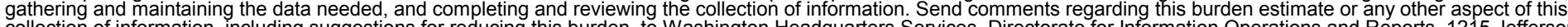
Davis Highway, Suite 1204, Arlington, VA 22202-4302, and to the Office of Management and Budget, Paperwork Reduction Project (0704-0188), Washington, DC 20503.
1. AGENCY USE ONLY (Leave blank)
2. REPORT DATE June 2001
3. REPORT TYPE AND DATES COVERED Technical Report

4. TITLE AND SUBTITLE

Vehicle Transient Air Conditioning Analysis:

Model Development \& System Optimization Investigations

5. FUNDING NUMBERS

HV11.7010, TP30715

6. AUTHOR(S)

Terry Hendricks

7. PERFORMING ORGANIZATION NAME(S) AND ADDRESS(ES)

8. PERFORMING ORGANIZATION REPORT NUMBER

9. SPONSORING/MONITORING AGENCY NAME(S) AND ADDRESS(ES)

National Renewable Energy Laboratory

1617 Cole Blvd.

10. SPONSORING/MONITORING AGENCY REPORT NUMBER

Golden, CO 80401-3393

NREL/TP-540-30715

11. SUPPLEMENTARY NOTES

12a. DISTRIBUTION/AVAILABILITY STATEMENT

National Technical Information Service

12b. DISTRIBUTION CODE

U.S. Department of Commerce

5285 Port Royal Road

Springfield, VA 22161

13. ABSTRACT (Maximum 200 words)

The National Renewable Energy Laboratory (NREL) has developed a transient air conditioning (A/C) system model using SINDA/FLUINT analysis software. It captures all the relevant physics of transient A/C system performance, including twophase flow effects in the evaporator and condenser, system mass effects, air side heat transfer on the condenser/evaporator, vehicle speed effects, temperature-dependent properties, and integration with a simplified cabin thermal model. It has demonstrated robust and powerful system design optimization capabilities. Single-variable and multiple variable design optimizations have been performed and are presented. Various system performance parameters can be optimized, including system COP, cabin cool-down time, and system heat load capacity. This work presents this new transient $A / C$ system analysis and optimization tool and shows some high-level system design conclusions reached to date. The work focuses on $\mathrm{R}-134 \mathrm{a}$ $\mathrm{A} / \mathrm{C}$ systems, but future efforts will modify the model to investigate the transient performance of alternative refrigerant systems such as carbon dioxide systems. NREL is integrating its transient air conditioning model into NREL's ADVISOR vehicle system analysis software, with the objective of simultaneously optimizing $\mathrm{A} / \mathrm{C}$ system designs within the overall vehicle design optimization.

14. SUBJECT TERMS

Transient air conditioning; optimization; SINDA/FLUINT; R-134a A/C systems; ADVISOR

17. SECURITY CLASSIFICATION OF REPORT Unclassified
18. SECURITY CLASSIFICATION OF THIS PAGE Unclassified
19. SECURITY CLASSIFICATION OF ABSTRACT

Unclassified
15. NUMBER OF PAGES

16. PRICE CODE

20. LIMITATION OF ABSTRACT

UL 